\title{
A review comparing cathodic arcs and high power impulse magnetron sputtering (HiPIMS)
}

André Anders

Lawrence Berkeley National Laboratory, Berkeley, California

email: aanders@lbl.gov

\begin{abstract}
High power impulse magnetron sputtering (HiPIMS) has been in the center of attention over the last years as it is an emerging physical vapor deposition (PVD) technology that combines advantages of magnetron sputtering with various forms of energetic deposition of films such as ion plating and cathodic arc plasma deposition. It should not come at a surprise that many extension and variations of HiPIMS make use, intentionally or unintentionally, of previously discovered approaches to film processing such as substrate surface preparation by metal ion sputtering and phased biasing for film texture and stress control. Therefore, in this review, an overview is given on some historical developments and features of cathodic arc and HiPIMS plasmas, showing commonalities and differences. To limit the scope, emphasis is put on plasma properties, as opposed to surveying the vast literature on specific film materials and their properties.
\end{abstract}

(C) 2014. This manuscript version is made available under the Elsevier user license http://www.elsevier.com/open-access/userlicense/1.0/ 


\section{Introduction}

Thin film deposition from the plasma phase, as opposed to from the neutral vapor phase, has been practiced for many decades. The presence of ions offers improved control of the film-substrate interface and the microstructure of films, where "improved" is the context of conventional physical vapor deposition (PVD) based on evaporation and sputtering. To limit the scope, this review focuses on (pulsed) cathodic arcs and high power impulse magnetron sputtering (HiPIMS), also known as high power pulsed magnetron sputtering (HPPMS) and under other names. The review will include pulsed sputtering with moderate amplitude, and bursts of pulses. We will see that some of the conceptual ideas in the cathodic arc and HiPIMS worlds are quite similar, and sometimes re-invented, while cathodic arc and HiPIMS also show very distinct differences. The motivation for this review is to provide a broader view at both technologies, their history, and their underlying physical mechanisms.

Cathodic arc and HiPIMS technologies are developed to supply ions that can assist in film formation as well as become incorporated in the growing film. Film synthesis from the plasma phase is sometimes called energetic condensation [1-8] or energetic deposition [9-13] - generally with the same meaning (and here interchangeably used), namely that plasma ions produce a film or coating, with each ion bringing significant kinetic and potential energies to the film growth process. The range of kinetic particle energies includes tens or even hundreds of electron-volts, which often exceed the displacement energy of atoms near the surface. The concepts of sticking probability and adsorption-desorption kinetics need to be re-examined since arriving ions may come to rest below the surface. As they remain with the substrate or growing film, their sticking probability can be considered unity, however, surface atoms may be knocked off in the process (desorption, sputtering). The energy of ions is largely controlled by the difference of plasma potential and substrate surface potential. The latter is most often determined by an intentionally applied bias voltage - a main parameter in energetic deposition. Besides kinetic energy, one should not neglect the potential energy that is also brought to the surface 
leading to atomic scale heating by both kinetic and potential energies [14]. The contribution of the ionization energy (from about $6 \mathrm{eV}$ to $10 \mathrm{~s}$ of eV, depending on the type and charge state of the ion) is large compared to energies needed for atoms to overcome diffusion and step barriers (they are of the order $0.1 \mathrm{eV})[15-17]$.

The review will start by very briefly looking at the historic development. We will then consider the physics of plasma formation in cathodic arcs and HiPIMS. While it is inevitable that one has to mention operation in dc (direct current / continuous) for both cathodic arcs and magnetron sputtering, emphasis is put on pulsed arcs in order appropriately compare the process with HiPIMS, a pulsed process of high power density. The considerations are then extended to variations such as modulated pulsed power (MPP) and burst processing. A compilation is given in tabular form at the end.

\section{A brief look at some early work}

Very early coatings by arcs and sputtering can be found in the $18^{\text {th }}$ and $19^{\text {th }}$ century [18-22], respectively, though the wide-spread industrial deposition of films using plasmas started in the second half of the $20^{\text {th }}$ century. Several patents were granted in 1939-1942 to Bernhard Berghaus, Wilhelm Burkard and Rudolf Reinecke [23-25] for what we call today ion plating. They feature plasma production and substrate biasing (Fig. 1).

(FIGURE 1)

Besides the effects of ions on film microstructure, the inventors also claim that plasma pretreatment, with the substrate negatively biased, has advantages in terms of adhesion - today sometimes called "(reactive) sputter cleaning" or "ion etching". It is interesting to read this in their own words: "The layers which are vaporised, especially on metallic articles, according to known methods, show very bad adhesion, and when the layers are very thick they show a porous and powder-like 
structure also on non-metallic articles. The following advantages are attained by the present invention. The glow discharge, with the article acting as a cathode, ensures reliable adhesion and the metallic deposit is so built up that it shows even with thicker layers, a perfect structure and adhering strength. It is especially advantageous if, before the vaporization of the material, the article, if metallic, is treated for a certain period of time by the discharge in a reducing atmosphere. With such a treatment all the impurities, such as oxides, traces of fat etc., are completely removed and, any coating will firmly adhere on the surface." [24]

As a source of condensable material, they describe vapor ionized by an electron beam, and sputtered atoms and ions (sputtering at that time was often called "cathode disintegration"). For example, in the patent granted in 1942, we find "This invention relates to a method of coating metal articles by cathode disintegration and it consists mainly in that the article is continuously or intermittently connected up as a cathode before or during the disintegration. The invention makes it possible to provide metallic articles with layers of any desired thickness, with perfect texture and great adhesion". [25] Texture and adhesion were then, and remain today, important topics of film deposition. The effect of ion bombardment was early recognized. For example, Ditchburn [26], in 1933, relates improved adhesion of films to a "cleaning effect of positive ions" in experiments on sputtering. In these works [23-26] we already find the key ingredients for energetic deposition: film-forming ("condensable") ions and bias to control the energetics of ions. The option to use pulsed or discontinuous bias is already mentioned. Already in these early systems, the condensable (metal) atoms were ionized by electron impact ionization [27-29] in the volume between electrodes of a dedicated auxiliary discharge, usually a thermionic arc $[30,31]$, i.e. a high-current low-voltage discharge using electrons from a hot cathode. The plasma density primarily depends power, for thermionic arcs mostly determined by discharge current, and is typically in the range $10^{17}-10^{18} \mathrm{~m}^{-3}$. 
In the 1960s, unaware of the early work, Mattox (re-)invented ion plating [32, 33]. Fig. 2 shows his principal apparatus, with the plasma formed by ionizing vapor and gas using electrons from a thermionic (hot) cathode. Ion plating developed rapidly in the 1960s and '70s, as evidenced by much patent activity for coating [34, 35] and cleaning by ion bombardment [36].

(FIGURE 2)

At about the same time, cathodic arc deposition was developed in the Soviet Union from a getter pump application to an industrial coating process. In contrast to thermionic arcs, the plasma formation processes in cathodic arcs are concentrated in very small, mobile cathode spots, as explained in greater detail in section 3 . The cathodic arc process was originally developed to produce TiN for decorative and corrosion-protection applications as well as for hard coatings on cutting tools, though also metal and oxide films were made. This development was kept secret and only years later became public $[37,38]$. The economic opportunities of cathodic arc coating were also realized in the United States, e.g., by Lucas [39]. Snaper obtained an important (influential) patent for a cathodic arc source in 1971 [40]. Both ion plating and cathodic arc deposition use plasmas to produce films and therefore are directly related to the subject of the review. However, they are continuous processes and therefore beyond the narrower scope of this review.

Pulsed arc systems were developed only for selected applications, such as the deposition of tetrahedral amorphous carbon [41]. Pulsed arcs can produce plasma from small cathodes, limiting and defining the region of plasma production. Besides, pulsed arcs produce less macroparticles than continuous, direct current (dc) arc systems [42]. Pulsed arcs could be easily combined with pulsed biasing, leading to new options of interface tailoring via intermixing and ion peening [43, 44].

Looking at sputtering, which is explained e.g. in refs. $[45,46]$ and further discussed in section 4 , one realizes that all the very early work $[19,20,22]$ was done in pulsed mode as continuous power supplies were not yet available. The necessary high voltage was obtained from low-voltage primary 
electrochemical cells in conjunction with Ruhmkorff induction coils [47] (self-interrupting step-up transformers). A huge step towards industrial use of sputter-deposition was done when a magnetic field was added such as the confine electrons and produce a closed drift path, as originally pioneered by Penning [48], and much advanced later by Chapin [49, 50], Clarke [51], Penfold and Thornton [52, 53]. Penfold [54] provided an interesting perspective of the early magnetron development and its legal battles, and Mattox offers a larger perspective in the context of the history of vacuum coatings technology [55].

Mid-frequency $(100-350 \mathrm{kHz})$ pulsing of magnetrons became very popular in the $1990 \mathrm{~s}$ as unwanted arcing was suppressed and the sputtering process could be scaled to very large areas with high deposition rate [56]. Even when high power was used for large areas, sputtered atoms are neutral atoms, not ions. A step towards plasma-assisted growth of films was done by using magnetically unbalanced magnetrons [57], where the plasma is used not only to facilitate sputtering but it is magnetically guided to the substrate location to assist film growth. The plasma can be guided via an unbalanced "closed" configuration e.g. by placing other magnetrons in the deposition system. A historic and scientific account of this development can be found in the review by Matthews [58].

Attempts to ionize sputtered atoms lead to the development of ionized sputtering, or ionized physical vapor deposition (i-PVD) [59], where an auxiliary radio-frequency (rf) discharge was added to the magnetron discharge [60-62].

For selected target materials with very high sputtering yield and/or vapor pressure (like $\mathrm{Cu}, \mathrm{Ag}$, $\mathrm{Bi}, \mathrm{Zn})$, high power operation of a magnetron can readily lead to ionization of the sputtered atoms, and the newly formed metal ions can at least in part take over the function of the sputtering gas (often argon): this is called self-sputtering and subject of research for several decades [63-66]. In the early implementations, non-planar (e.g. hollow cathode, cylindrical) magnetrons were used as confinement of 
energetic electrons can be achieved easily in such geometries. This approach was especially important for metallization applications in the semiconductor industry [67].

To push sputtering power even higher, thereby enabling ionization of practically all kinds of target atoms, the power must be supplied in pulses to avoid overheating, magnet damage, and/or target melting. A general concept in pulsed power technology is that very high pulse power (e.g. MW) can be reached with rather conventional average power (e.g. kW) when the pulse duty cycle $\delta=t_{\text {on }} /\left(t_{\text {on }}+t_{\text {off }}\right)$ is kept much smaller than unity. For example, "superdense" pulsed hollow-cathode discharges were investigated by Abramovich and coworkers in the 1960s [68], and high current (up to $3 \mathrm{kA}$ ) pulsed glow discharges were developed as black body light sources for spectroscopy by Malkin and coworkers in the early 1970s $[69,70]$. In the late 1980s, Oks and co-workers developed a $15 \mu$ s pulsed cylindrical magnetron discharge as a source of electrons, with the $\mathbf{E} \times \mathbf{B}$ discharge reaching 1 kA [71, 72]. Another relevant development from the 1980s and '90s are so-called pseudospark discharges [73] operating without arc spots at low pressure ( $<1$ mTorr), short pulses ( $1 \mu \mathrm{s})$ and very high currents (up to $100 \mathrm{kA})$, which has been associated with self-sputtering [74].

In the context of pulsed sputter deposition, application of pulsed power technology leads to high power pulsed magnetron sputtering (HPPMS). To imply very high power and very low duty cycle, the word "impulse" can be used [75-77], leading to high power impulse magnetrons sputtering (HIPIMS, or recently more frequently HiPIMS). The word "impulse" is quite common in the Russian literature [70] and occasionally also used for pulsed arcs [78].

Earlier developments in Russia in the 1990s [79, 80] demonstrated pulsed high power magnetron discharges achieving a high degree of ionization, high ion fluxes, and very high deposition rates, e.g. for $\mathrm{Cu}$ and $\mathrm{Ti}$. Bugaev and coworkers [80] used an assisting discharge, and specifically a thermionic arc discharge, to help establishing high power pulses without transition to the cathodic arc mode. 
An important publication on HPPMS or HiPIMS by Kouznetsov and coworkers [81] appeared in 1999. While not the first publication in this field, it can be considered seminal as the concept of ionization of sputtered target atoms was clearly demonstrated with a conventional planar magnetron operated at common average power and without any assisting discharge. High metal ion fluxes and a high degree of ionization obtained this way were soon confirmed by other groups [82-87].

\section{Cathodic arc plasma production, with emphasis on pulsed arcs}

Pulsed cathodic arc discharges are cold-cathode arc discharges $[1,88]$ of very limited duration, often $100 \mathrm{~s}$ of $\mu \mathrm{s}$, or even shorter. The basic plasma-formation processes occur at cathode spots [89]: small areas $\left(\sim 10^{-14}-10^{-10} \mathrm{~m}^{2}\right)$ of very high current density $\left(\sim 10^{10}-10^{12} \mathrm{~A} / \mathrm{m}^{2}\right)$ and related high power density $\left(\sim 10^{11}-10^{14} \mathrm{~W} / \mathrm{m}^{2}\right)$, where the cathode surface material is extremely rapidly transformed from solid to plasma [90] due to the combined action of ion bombardment and Joule (Ohmic) heating. Plasma parameters (and related information) of cathodic arcs are listed in Table 1 for comparison with other processes. The condition for discharge ignition and plasma formation are briefly explained later in this section.

Plasma formed at small, mobile cathode spots consists of cathode material, and a process gas does not need to be present. However, argon gas has been found to promote discharge stability, and reactive gas is needed when the goal is to deposit compound films. In the absence of any gas one speaks of vacuum arcs $[88,91]$. The rapid repeated initiation of cathode spot is closely associated with the presence of a very high electric field at the cathode surface, which can be readily achieved despite the low total voltage between cathode and anode ( $20 \mathrm{~V})$ because most of the voltage drops in a very thin space charge layer (sheath) adjacent to the cathode (also known as the cathode fall). The actual magnitude of the electric surface field is greatly affected by geometrical features such as microscopic 
protrusions [92] or cracks [93], as well as by non-metal features such as adsorbates, oxide layers, and dust particles [94].

Depending on the surface condition, metallic-clean versus covered with a non-metallic layer or contamination, one can find two different types of arc spots and erosion traces $[89,95]$. In the clean surface case, arc spots are relatively bright, move relatively slowly, make large erosion craters ( $\mu \mathrm{m})$, and produce large $(\mu \mathrm{m})$ macroparticles. In contrast, cathodes with a non-metallic overlayer generate spots that move fast, with small, shallow, disconnected erosion craters and produce small macroparticles. As the action of the arc removes cathode material, thereby cleaning the cathode, spot types can change during the discharge. A good way of remembering the conventional numbering of spot types is that the arc could start on a non-treated, contaminated surface with spot type 1 (the one with small, fast moving spots), and continues to operate on a cleaned cathode with spot type 2 (the one with large, bright, slow moving spots). For many practical applications, where compound films are needed, one adds a reactive gas into the deposition chamber to intentionally "poison" the cathode, i.e. to form a compound layer and thereby letting the arc burn with type 1 cathode spots. While the deposition rate is reduced in the "poisoned" mode, it is still high enough to be economical. In contrast to magnetron sputtering, the process window for reactive deposition is wide and one can obtain stoichiometric compound films with reasonable effort in reactive gas process control. This is especially true for pulsed arc operation, when there is plenty of time between pulses for the reactive gas to react with atoms on the surface of the cathode and the surface of the substrate.

The detailed processes of plasma formation in cathode spots are complicated as there are strong gradients for practically all physical parameters. Plasma formation is closely related to the electron emission mechanism, which is thermally unstable thermo-field emission [96, 97], a locally concentrated, non-linear superposition of field emission $[98,99]$ and thermionic emission [100]. This is also known as explosive emission [101], and the arc spot may be considered as a sequence of rapid 
microscopic explosions $[92,102]$. A concept for highly localized phase transition of the cathode material from solid to plasma is thermal runaway: the electron-emitting site usually starts where the electric surface field is very high, i.e. at locations of electric field enhancement due to various reasons (e.g. geometric: protrusions, cracks; or textural: grain boundaries; or chemical: dust inclusion). The emitting site is heated by ion bombardment as well as by Joule heating in the solid as electrons are supplied to the emitting site. As the site gets hotter, electron emission increases in a highly non-linear fashion as field emission is synergistically amplified by thermionic contribution until emission cooling and heat conduction terminate this process $[1,89,103]$.

The current density at cathode spots is central to any model of cathode spot operation and was therefore the subject of many investigations. Today there is consensus that the current density is a fluctuating (fractal, see below) quantity that can be as high as $10^{12} \mathrm{~A} / \mathrm{m}^{2}[89,104]$. The associated power density can be obtained by considering the voltage drop in this region, which is of order $10 \mathrm{~V}[105,106]$, hence the power density is also variable up to $10^{13} \mathrm{~W} / \mathrm{m}^{2}$. This is comparable with power densities used in laser plasma ablation, and it should not be surprising that pulsed laser ablation plasmas can be similar to cathodic arc plasmas [107].

The cathodic arc inherently emits plasma of the cathode material as well as infamous "macroparticles", i.e. microscopic hot cathode debris particulates or droplets $[108,109]$ which are easily visible when the cathode is graphite or a refractory metal (Fig. 3).

(FIGURE 3)

The physics of cathode processes, plasma properties, and features of macroparticles are summarized and reviewed in chapter 3 of [1]. As a result of microscopic explosions, the cathode is eroded in small portions, the traces of which are visible in electron micrographs as microscopic craters (Fig. 4).

(FIGURE 4) 
The size distributions of craters and macroparticles are related and given by power laws [108, 110]. Many other parameters such as the voltage "noise" distribution [111], which can be determined by Fast Fourier Transform (FFT) of the arc burning voltage, also show power law distributions [112, 113]. In the fields of chaos and self-organization it is well known that power laws [114]

$$
f(x)=a x^{b}
$$

are the "fingerprints" of fractals or self-similar objects because they are invariant to a change of scale (a power law remains a power law upon multiplication). It has been argued that cathodic arcs fractals showing self-similarity [115] at different length and time scales down to the physical cutoffs [110]. The physical cutoffs are determined by the smallest explosion that can be produced, which Mesyats called "ecton" $[116,117]$. In practical terms, the cutoff of self-similarity is expected in nanoseconds in time and $10 \mathrm{~nm}$ in length. The time cutoff is derived by the observation of smoothing of a surface, rather than crater formation, when the discharge pulse duration is less than $5 \mathrm{~ns}$ [94]. The lower limit of the length scale is found from the smallest macroparticles and crater sizes [118, 119].

The ignition of cathode spots has much in common with high voltage electrical breakdown [92, 120]. Both are based on high electrical field strength on the surface. In the case of an arc that is already operating, the field strength can be as high as the ones seen for high voltage breakdown because the length scale for the cathode fall is small $(<1 \mu \mathrm{m})$. At this scale, local features, geometric and/or composition and texture, are important. Furthermore, the action of the field and the plasma change the local surface conditions. An extreme example is the flow of metal via electromigration (Fig. 5) [121].

(FIGURE 5)

Microscopic explosions provide transient plasma, with the initial plasma density close to the solid state density of the cathode. As it is typical for point-like sources, the density drops with $d^{-2}$, where $d$ is the distance from the center of the explosion. As long as the approximation of a point 
source is good, i.e. for arcs of relatively low current with one spot, the plasma density can be estimated by

$$
n=C \frac{I_{a r c}}{d^{2}} \cos ^{\alpha} \vartheta
$$

where $I_{\text {arc }}$ is the arc current, the cosine factor describes a Lambertian distribution, with the angle $\vartheta$ measured relative to the cathode normal; the exponent $\alpha$ is of order 1 and describes the pointiness of the Lambertian shape, and $C$ is a constant determined by the material-specific erosion (for copper $\left.C \approx 10^{13} \mathrm{~A}^{-1} \mathrm{~m}^{-1}[89,122]\right)$. Ivanov and colleagues showed that the electron density indeed drops like $d^{-2}$ [122], which implies that the plasma composition, i.e. the ion charge state distribution, remains almost unchanged or "frozen" during expansion [123]. It is quite common for rapidly expanding gases and plasmas to drift into non-equilibrium as the rate of collisions between particles rapidly drops. Conversely, at very high density, the collision rate is high and the system can be close to equilibrium. The ionization equilibrium is given by a system of ionization and recombination rate equations, the Saha equations [124]. In [125] it was assumed that Saha ionization equilibrium can be applied to the plasma of cathode spots, while the expanded plasma far from the spot center is in a non-equilibrium, frozen state. Ion charge state measurements far from the cathode spot can then be used to determine the plasma conditions in the transition region between equilibrium and non-equilibrium, which was determined to be about $100 \mu \mathrm{m}$ from cathode spot center [123]. In particular, the cathode materialdependent electron temperature could be determined, which is in the range from $1.5 \mathrm{eV}$ to $4.5 \mathrm{eV}$ for type 2 spots on pure metal cathodes [125].

Later measurements of the ion charge state distributions as a function of distance $[126,127]$ showed that they are not as really "frozen" as assumed, rather, charge exchange collisions [128] of ions with neutrals lead to a gradual shift from higher charge states to singly ionized ions. Therefore, the 
charge states and related electron temperatures in and near cathode spots are even higher than tabulated in [125].

The high kinetic energies of ions are another striking feature, which is especially relevant for the deposition of films from cathodic arc plasma. The energies are generally in the range from about $20 \mathrm{eV}$ (for carbon) to about $120 \mathrm{eV}$ (for refractory metals like W) [129], where the energy distribution shows generally one broad peak $[130,131]$. Ion acceleration occurs close to the cathode spot, in the region where ionization is prevalent and close to equilibrium. It is generally assumed that the very strong gradients in electron and ion pressure are the main forces for acceleration [132]. As electrons cannot expand freely due to Coulomb forces between electrons and ions, acceleration is a collective phenomenon [132].

Phase transitions require material-specific energies. The energy input to the discharge is determined by the power dissipation, i.e. the product of the current and the voltage drop between anode and cathode, which primarily happens in the cathode sheath. An semi-empirical energy rule can be formulated, where the properties of cathodic arc plasma are related to the voltage drop $V$ in the cathode layer, which is correlated to the strength of the bonding of cathode atoms as expressed by the cohesive energy $E_{C E}$. The rule is therefore called the Cohesive Energy Rule $[113,133]$ and can be written as

$$
V=V_{0}+a E_{C E},
$$

with $V_{0} \approx 14.3 \mathrm{~V}$ and $a=1.69 \mathrm{~V} /(\mathrm{eV} /$ atom $)$. The numerical values were derived from measurements of pulsed arcs (150 $\mu$ s after arc pulse start) with currents of the order of $100 \mathrm{~A}$ and may vary somewhat when conditions are different. There are secondary (derived) rules related to arc parameters, like the average ion charge state and ion kinetic energy (Fig. 6).

(FIGURE 6) 
Many fundamental studies of arc operation have been done in vacuum in order to keep the system as simple and as reproducible as possible. However, the majority of cathodic arc coating applications are done in a low-pressure background gas: argon is commonly added as the arc tends to burn in a more stable manner, and reactive gas is added to obtain compound films. Therefore, it is very appropriate to study arc processes in gases. Figure 7 shows one of those studies. Here, the ion energy distributions were measured as a function of the product of pressure and distance from the cathode because both parameters affect the mean free path. One can see that, starting from the energy distribution in vacuum, ions of the energetic peak are increasingly thermalized by losing energy to the background gas. In the extreme case, at large $p d$ products, only thermalized ions are left. Thermalization goes along with the loss of the higher ion charge states as they are stepwise reduced by charge exchange collisions, which initially may occur with neutral argon atoms (provided the energy and momentum balances work out)

$$
M^{n+}+A r \rightarrow M^{(n-1)+}+A r^{+} \text {for } \mathrm{n} \geq 3
$$

and also with neutral cathode atoms as they become available [127]:

$$
M^{n+}+M \rightarrow M^{(n-1)+}+M^{+} \text {for } n \geq 2
$$

(FIGURE 7)

For high current pulsed arcs, e.g. with currents of $1 \mathrm{kA}$ and higher, several (many) cathode spots are simultaneously emitting plasma. The density formula for a point source, Eq. (2), is no longer valid, rather, we deal with a superposition of point emitters. The high current also generates a magnetic field that affects the direction of subsequent spot emission (apparent motion of cathode spots) and the expansion of plasma. Fast camera images of pulsed high current arcs show a growing ring of cathode spots [42]. In time-integrating, open-shutter photographs the spots appear like a fractal star pattern 
(Fig. 8). The magnetic field caused by the current filaments from neighboring cathode spots affects the spot motion as well as the plasma transport from the cathode.

(FIGURE 8)

This apparent repelling of cathode spots has been used to develop a pulsed high current arc source with a central trigger. The pulse length is tuned in such a way that the pulse terminates when the arc spots reach the rim of the cathode disk or rod [42]. For greater convenience, flexibility and reliability, triggering can be done with a pulsed laser: the "laser arc" deposition is primarily a high current pulsed arc, where the laser plasma plume is not used for coating but for initiating and timing the pulsed arcs [134]. Triggering can also be done electrically, either with a surface flashover trigger [135], or via forming a hot spot through a coating. In the latter case, no dedicated trigger electrode is needed, hence it was called "triggerless" arc initiation [136].

While many studies have been done with elemental cathodes, any material can be used as an arc cathode as long as it is sufficiently conducting. For example, some arc studies focused on alloy or sintered cathodes due to their relevance for multicomponent coatings [17, 137, 138], also an important topic for the HiPIMS counterpart development discussed in the next section.

\section{Pulsed plasma production by HiPIMS}

It has been a long standing goal to combine magnetron sputtering with ion assistance to film

growth. After the already-mentioned approach of i-PVD, adding an auxiliary RF-discharge to a magnetron [59, 139], very significant ionization of sputtered atoms was demonstrated high power pulses $[81,140]$. HiPIMS requires high currents, usually 10 s to 100 s of amperes, and is therefore practiced with conducting (usually metal) targets (not unlike a cathodic arc!). 
All metal atoms have significantly lower first ionization energy than noble gases [28] (typical example: $\mathrm{Cu}$ atoms require $7.73 \mathrm{eV}$ to become ionized, while argon needs $15.76 \mathrm{eV}$ ). Therefore, metal atoms are more readily ionized in the magnetron plasma than noble gases, provided they did not travel too fast from the target surface through the discharge plasma. Once ionized, the newly formed metal ion is subject to acceleration by the local electric field, in this case the electric field of the magnetic presheath [141]. This electric field, the derivative of the plasma potential, is directed towards the target. This statement is true in a time-averaged sense but locally it varies in a transient manner, as explained later. The plasma potential has be measured with a (pulse-heated) electron-emitting probe [142], except in the region close to the racetrack because the presence of a probe disturbs the discharge. Fig. 9 shows the time-averaged potential distribution [143]: the funnel shape of the potential is related to the structure of the magnetic field that captures electrons and causes the well-known $\mathbf{E} \times \mathbf{B}$ drift (where $\mathbf{E}$ and $\mathbf{B}$ are the electric and magnetic field vectors, respectively).

(FIGURE 9)

There is ample literature on sputtering in general, e.g. [45, 144, 145], and therefore here we can focus on HiPIMS and the fact that ionization is not uniformly distributed. Power dissipation is nonuniform in several respects; however, many equipment brochures and technical reports simply mention "power density". This is generally a nominal power density defined as the power (= voltage * current) divided by the target area. While the nominal power density is a helpful value to get oriented, it substantially underestimates the physically relevant power density. First, most plasma is generated over the racetrack, and not over the entire target area (hence a linear power density, expressed in $\mathrm{W} / \mathrm{m}$, could be alternate useful quantity). Second, the plasma over the racetrack is bunched in moving ionization zones [146-148], also known as spokes $[149,150]$ in analogy to observations made with plasma thrusters $[151,152]$. Such spokes, or ionization zones are known for decades [153] and characteristic for all kinds of E x B devices, not just sputtering magnetrons. Yet, only recently they were 
appreciated to determine ionization and transport physics in the context of HiPIMS. This will be closer examined later in this review.

Important features of HiPIMS plasma production include sputtering by ionized sputtered atoms, i.e. self-sputtering [64-66], which can run away to very high levels if the power supply is capable of delivering the necessary current at the required sputtering discharge voltage [154]. The most clear demonstration of self-sputtering is achieved when eliminating the process gas altogether, which can be done by turning off the gas supply after starting the discharge $[155,156]$, or by choosing operation in high vacuum and starting HiPIMS pulses by a small "puff" of plasma from a short-pulse cathodic arc source $[157,158]$.

Sustained self-sputtering without process gas is only possible for materials with very high selfsputtering yield. In other words, most target materials cannot be run in a pure self-sputtering mode: one needs a process gas like argon to operate the magnetron. Somewhat surprisingly, runaway to high currents can be observed for all materials, even for carbon (graphite), a material of very low selfsputtering yield. It is believed that the repeated supply of gas neutrals contributes to high current levels. Gas ions that are not bonded in the growing film, like noble gas atoms, return to the pre-target region as neutrals, where they can be again ionized. The cycle of ionization and neutralization can repeat often, as can the process of sputtering, ionization, and return to the target. This is schematically shown in Fig. 10 [159].

(FIGURE 10)

The probability of an ionizing collision depends on the density of neutral atoms to be ionized and the relative velocity $u$ of the electron with respect to the atom. The mean-free-path of an electron between ionizing collisions, $\lambda_{e}$, is given by [160-162]

$$
\lambda_{e}=\left(\sum_{a} n_{a} \sigma_{e a}\right)^{-1}
$$


where $n_{a}$ is the atom density and the summation is over all types of atoms, and $\sigma_{e a}(u)$ is the cross section for ionization [28] (the index "e" is for electrons and "a" for atoms). More general, one can consider $\sigma_{e a}(u)$ as the total cross section for all kinds of electron-atom interaction and then obtains the general mean free path of an electron. The mean time between collisions is $\tau_{e}=\lambda_{e} / u$, and the mean collisions frequency is the inverse,

$$
\tau_{e}^{-1}=\frac{u}{\lambda_{e}}=\sum_{a} n_{a} \sigma_{e a} u
$$

Since we do not have a single velocity but a velocity distribution, one averages over the distribution function, $f_{e}(u)$, and expresses the collision frequency as

$$
v_{e}=\sum_{a} n_{a}\left\langle\sigma_{e a} u\right\rangle
$$

with

$$
\left\langle\sigma_{e a} u\right\rangle=\frac{1}{n_{e}} \int_{0}^{\infty} \sigma_{e a}(u) u f_{e}(u) d u
$$

as a rate of collisions. From (8) and (9) we see that the ionization frequency is proportional to the atom density and the weighted product $\sigma_{e a}(u) u f_{e}(u)$, i.e., we need electrons with an energy where the ionization cross section is large. For most atoms, the maximum of the ionization cross section is in the region $50-100 \mathrm{eV}$, i.e. the discharge is most effective when electrons are given at least the ionization energy of atoms, and preferably several $10 \mathrm{~s}$ of eV. Very energetic electrons, with hundreds or thousands of $\mathrm{eV}$, are not effective unless they are trapped via geometric means (like opposing sheath of a hollow cathode), or via a closed drift facilitated by a magnetic field, like done in a magnetron [52].

This leads to the conventional Penning-Thornton paradigm of electron heating and plasma generation $[52,163]$ : it is generally assumed that the secondary electrons are the main energy source because they gain energy from the sheath adjacent to the target (cathode) and are then capable of 
producing many electron-ion pairs in ionizing collisions. Thornton [52] formulated a condition for the minimum voltage required to maintain the discharge, which in its simplest form can be written as

$$
V_{\text {discharge }} \geq \frac{E_{i, e f f}}{\gamma_{S E, e f f}}
$$

$E_{i, e f f}$ is the effective energy cost for the average ion-electron pair created, and $\gamma_{S E, \text { eff }}$ is the effective secondary electron emission yield. The effective yield is smaller than the commonly tabulated values of the secondary emission yield $\gamma_{S E}$ because emitted electrons are likely recaptured by the cathode (target) due to the curved electron trajectory in the magnetic field. The emission formula needs to include the escape probability $p_{\text {escape }}$, which is complementary to the recapture probability $p_{\text {recap }}$, i.e. $p_{\text {escape }}=1-p_{\text {recap }}$, and $\gamma_{S E, \text { eff }}=p_{\text {escape }} \gamma_{S E}$. The local current density for secondary electron emission is thus

$$
j_{S E}=p_{\text {escape }} \gamma_{S E} j_{i}
$$

where $j_{i}$ is the local current density of ions arriving at the target.

The issue of very low secondary electron emission is aggravated when singly charged metal ions replace the noble gas ions during each HiPIMS pulse [164]. The yield for singly charged metal ions is zero based on Baragiola's empirical yield formula for clean metal targets [165]

$$
\gamma_{S E}=\left\{\begin{array}{cc}
0.032\left(0.78 E_{p o t}-2 \phi\right) & \text { for } E_{p o t}>2 \phi \\
0 & \text { else }
\end{array} .\right.
$$

where $E_{p o t}$ is the potential energy of the impacting ion (ionization energy, e.g. $6.82 \mathrm{eV}$ for $\mathrm{Ti}^{+}$), and $\phi$ is the work function (e.g. $4.3 \mathrm{eV}$ for Ti). The discharge must therefore find other ways to provide energetic electrons capable of causing ionizing collisions, or it becomes unstable and extinguishes. Possible energy supply mechanisms include the generation of doubly and higher charged ions [164], 
photoemission, or heating by a mechanism other than Penning-Thornton. Such other mechanism was recently presented by Huo et al. [166]: they argued that the voltage drop in the magnetic presheath can lead to a very significant energy dissipation and electron heating. Even as that voltage drop is much smaller than the voltage drop in the sheath, the flux of electrons (i.e., the electron current) is much greater in the presheath, and hence the presheath heating effect can be comparable or even greater than the conventionally assumed mechanism. Measurements of the electron distribution function, at a distance of $10 \mathrm{~cm}$ from target, do not show any high energy electrons but a two-peaked distribution with the both peaks near $1 \mathrm{eV}$ [167], indicative for heated and thermalized electrons.

Taking this line of thought one step further, one should have a closer look at the potential structure in the presheath, and take into account the many spatial and temporal variations $[147,148$, 168, 169]. As shown in Eq. (8), the ionization events are directly proportional to density of atoms to be ionized, and to the density of energetic electrons. Spectroscopic imaging with high time resolution revealed that the ionization events tend to be localized in ionization zones. Spectroscopic images (Fig. 11) showed that the higher the ionization energy and the higher the level of excitation the more localized is the light emission, which is indicative for the rate of excitation and ionization [170].

(FIGURE 11)

The transition between dense and less-dense plasmas is characterized by an electric double layer [171]. This lead Brenning and coworkers [149] to suggest that the ionization zone could be the location of a potential step. To be consistent, the potential changes along the racetrack direction need to cancel when considering that the drift path over the racetrack is closed, as the electrons arrive at about the same position when drifting all around the target. From that one may deduce that the potential changes associated with each ionization zone, taken along the coordinate $\xi$ in the direction of the racetrack, must approximately vanish [169], i.e., 


$$
\int_{\xi_{\text {start }}}^{\xi_{\text {end }}} \frac{\partial V(\xi)}{\partial \xi} d \xi \approx 0,
$$

where $\xi_{\text {start }}$ and $\xi_{\text {end }}$ are the start and end coordinates of the ionization zone in the $\xi$-direction. In other words, the ionization zone represents a potential hill which is enclosed by an electric double layer [169]. Considering a path in the $\xi$-direction at a certain distance $z$ from the target, the potential hill appears enclosed by double layers whose potential steps cancel (Fig. 12).

(FIGURE 12)

There are many consequences from the assumption of the potential hump associated with an ionization zone:

- Ions leaving the potential hump are accelerated in all directions: (i) if generated close to the target, they will be accelerated to the target and cause sputtering; (ii) if generated relatively far from the target, they get accelerated to the substrate and contribute to the high-energy nonThompson part of the ion energy distribution function (IEDF) (Fig. 13) [172]. The clear nonThompson part of the IEDF is universally observed, including for HiPIMS discharges of short duration [173].

- Ions generated on the upstream part of the potential hump can "surf" this potential wave and gain more energy than the ions generated on the downstream part of the hump. As a result, ions are accelerated sideways, and preferentially in the direction of the hump motion, i.e. in the $\mathbf{E} \times \mathbf{B}$ direction [174] (Fig. 14). Ionizing collisions occur at various distances from the target. The distributions shown in Fig. 14 suggest that argon ions are likely to be produced at a greater distance from the target than metal ions because they show less the effects of moving potential humps. This is consistent with spectrally resolved imaging [170] which shows light emission from metal concentrated near the target (within millimeters), while emission from argon can be seen at larger distances (Fig. 15). 
- Electrons encountering the electric field of the double layer can drastically change the direction of their $\mathbf{E} \times \mathbf{B}$ drift: on one side of the potential hump the local $\mathbf{E} \times \mathbf{B}$ direction points away from target. As a consequence, plasma can escape and form jets or flares: this has been observed using fast cameras (Fig. 15) [170, 175] and probes [174]. The disruption of the "regular" $\mathbf{E} \times \mathbf{B}$ drift helps to explain why magnetron discharges, and in particular HiPIMS discharges, can reach very high currents. Of course, electrons are also subject to drifts other than $\mathbf{E} \times \mathbf{B}$, e.g. the $\nabla B$-drift. Ultimately 3D-simuations are needed to elucidate the details of the complicated plasma flow.

(FIGURE 13)

(FIGURE 14)

(FIGURE 15)

The interaction of the plasma formed near the target with the background gas may lead to background gas "activation": dissociation (for molecular gases, if applicable), excitation, and ionization. However, this interaction comes at an expense, namely the average ion current density drops quickly with increasing distance from the target [176] (Fig. 16).

(FIGURE 16)

\section{Burst of pulses and other extensions}

As with each pulse technology, there are parameters, such as on and off times, that can be varied to optimize the system for best performance. In some cases it is desirable to group pulses to a burst in order to make use of the conditions produced by the preceding pulse. Burst operation can be further refined by structuring the sequence of pulses (pulse on/off, and amplitude) within a burst. 
In cathodic arc processing, the benefit of burst operation is limited because plasma production occurs at cathode spots of extreme power density and short spot time scales, and thus the effect of a preceding pulse is small unless one tries to affect the cathode surface conditions. For arcs, the effect of bursts is mostly indirect as the arc spot action changes the condition of the cathode, and thereby affects the spot ignition probability and statistical spot lifetime.

In contrast, burst operation in the case of HiPIMS can have profound effects as the plasma development of each pulse is affected by the afterglow plasma from the previous pulse. The current level and power of each pulse is therefore increased as a pulse is placed closer to the preceding pulse, which affects the plasma composition and the entire performance of the system. Using a specific power supply of long pulses, where each long pulse is composed of underlying "micropulses", allows us to tune the current-voltage relation by spacing of the micropulses. Such concept was realized in the Modulated Pulsed Power (MPP) sputtering system by the company ZPulser [177], characterized e.g. by Meng and coworkers [178]. Lin and coworkers combined this with dc sputtering to form CrSiN coatings [179]. More recently, ZPulser offered an advanced version of a power supply for "deep oscillation" magnetron sputtering [180], which can be also be seen as an approach to sputtering using bursts of pulses. Fig. 17 shows an example of a HiPIMS burst, where each burst has two segments. The current of the second segment is enhanced not because the applied voltage is greater but because the pulse on and off times have been changed [181]. In another work it was shown that the inductance of the system causes the current to stay on, even as the applied voltage is briefly switched to zero between individual pulses [182].

(FIGURE 17)

Following up on an idea from the original i-PVD work $[139,183]$, namely that the degree of ionization can be enhanced by adding an additional rf-discharge to the magnetron discharge, Stranak and coworkers [184] developed "enhanced HiPIMS": they showed that adding an Electron Cyclotron 
Wave Resonance (ECWR) discharge in the time between HiPIMS pulses let to an increase in the fraction of doubly charged ions during the HiPIMS pulse. With plasma already present at the beginning of each pulse, the current can rise faster, and the peak current can be higher [185]. Higher power density leads to a greater degree of ionization and the formation of multiple charge states [87, 181, 186-189].

\section{Biasing}

Since the early work of Bergman and others on the 1930s, the application of a bias voltage to the substrate has long been recognized as an important tool to control the energy of ions and thereby the adhesion and microstructure of coatings. In 1985, Adler and Picraux [190] proposed to synchronize the production of pulsed arc plasma and high voltage biasing, where the biasing is delayed to account for the time of flight of the plasma ions from the ion generator to substrate. In their case, bias was as high as $-80 \mathrm{kV}$, leading to ion implantation. This idea was generalized by Conrad et al. [191] who proposed the general principle of Plasma Source Ion Implantation (PSII), and by Brown et al. $[43,192]$ to develop metal plasma immersion ion implantation and deposition (MePIIID). Operating in the intermediate energy range between typical displacement energies (30-40 eV) and conventional ion implantation energies (100 keV and greater), the bias system can be tailored to obtain shallow ion implantation (a.k.a. subplantation [193]), or/and to assist in interface tailoring and film growth [15, 194].

When the substrate is conducting, bias is preferably applied in continuous (dc) manner or in pulses. By its very nature, an insulating substrate cannot be biased unless one uses the capacitive effect of rf-biasing. All of those bias types can be applied with arc and HiPIMS plasmas. Historically, the principles and the effects of biasing were demonstrated with arc plasmas years before HiPIMS was invented.

High voltage $(>1 \mathrm{kV})$ dc-biasing for substrate sputtering (cleaning) interface preparation was widely used in the arc-bond sputtering (ABS) process introduced in the early 1990s [195, 196]. This 
approach has been extended using filtered arc plasmas [197], and over the last years more often to HiPIMS plasmas [77, 198-200].

In the early 1990s, pulsed bias was explored in conjunction with pulsed arcs, where the duration of the bias could be selected to be shorter than the duration of the arc plasma pulse. By phase-shifting plasma production and bias, it is possible to have times dominated by deposition (absence of bias, or low bias), and times dominated by ion implantation and surface atom removal (sputtering) [43]. By selecting desirable proportions of ion implantation (high voltage bias) and deposition (no or very low bias) one can arrive at elemental composition depth profiles that are unattainable by conventional ion implantation, a process that could be called "pseudo-implantation" [201].

Also in the early 1990s it was recognized that much lower dc-bias superimposed with higher voltage pulses can be used to affect film microstructure [202], a topic that is much researched today in the context of HiPIMS. For example, Bandorf and coworkers [203] investigated the effects of superimposed bias for NiCr films, and Vergöhl and colleagues [204] considered the superposition of midfrequency (mf) and dc on the microstructure for $\mathrm{ZrO}_{2}$. Modern power supply offer today great flexibility in superimposing dc, mf, and HiPIMS pulse patterns.

Various combinations of $\mathrm{dc}$ and pulsed plasmas and bias relations can be considered. For example, it might be practicable to produce long plasma pulses in combination with higher frequency bias pulses (Fig. 18). In other words, one may use pulse bias where the bias on-off relation determines the relative phases of ion implantation (or subplantation [205] or ion-assisted growth [206, 207]) to biasfree deposition. Major goals of this approach were to produce coatings that are well-adherent, dense, and smooth $[202,208]$.

(FIGURE 18)

Phase-shifting the bias with respect to the plasma offers even more possibilities when the plasma varies not just in density but in composition. This can been realized using a pulsed cathodic 
plasma source with more than one cathode $[209,210]$. For example, for the deposition of tetrahedral amorphous carbon (t-aC), the most diamond-like material in the family of diamond-like materials, it is desirable to apply bias of about $-100 \vee[211,212]$. Such bias is too high when also metal plasma is supplied: the impact of the energetic metal ions would degrade the fraction of $\mathrm{sp}^{3}$ (diamond) bonds. In this case, bias was applied when carbon ions were supplied, and no bias was present when metal plasma arrived at the substrate. Such "species-selective bias" [209] can be used in many applications to optimize the introduction of desired elements, e.g. molybdenum to tailor conductivity [213], or silver to obtain antibacterial properties [214].

For HiPIMS, the plasma composition changes within each pulse as sputtered atoms enter the dense plasma and become ionized [85, 186, 215-217]. This suggests that bias could be phased with plasma composition to assign higher energy to either the gas or metal, depending on the requirements of the application. This has been carefully studied for the $\mathrm{Ti}_{1-x} \mathrm{Al}_{x} \mathrm{~N}$ system by Greczynski and co-workers [218]. They chose $x$ to be about 0.61 near the kinetic solubility limit at the growth temperature of $500^{\circ} \mathrm{C}$. Three sets of experiments were carried out: $-60 \mathrm{~V}$ substrate bias was applied (i) continuously, (ii) synchronously with the full HIPIMS pulse, (iii) synchronously with the metal-rich plasma portion of the HiPIMS pulse. Films grown under continuous bias exhibited a small-grain, two-phase nanostructure of wurtzite $\mathrm{AlN}$ and cubic $\mathrm{Ti}_{1-\mathrm{x}} \mathrm{Al}_{\mathrm{x}} \mathrm{N}$ with random orientation and 0.2 at.\% $\mathrm{Ar}$ incorporation and high compressive stress of $4.6 \mathrm{GPa}$. Synchronizing the bias with the full HIPIMS pulse lead to much lower stress (1.8 GPa) with no measureable Ar incorporation, larger grains elongated in the growth direction, a very small volume fraction of wurtzite AIN, and random orientation. Synchronizing the bias with the metal-rich plasma phase of the HiPIMS pulses resulted in single phase films with a dense competitive columnar structure, strong (111) orientation, no measureable trapped Ar concentration, and even lower stress (0.9 GPa). This example demonstrates the benefits of phased bias. 
In most systems the plasma potential is close to ground as the anode of the plasma-generating source (cathodic arc plasma source or high power pulsed magnetron) is grounded. This is due to the high mobility of electrons, as the plasma approximately assumes a slightly higher potential (by $\square k T_{e} / e$, i.e. a few volts) than the most positive surface it is in contact with. Biasing of the substrate is practically done with respect to ground, with implies it is approximately realized with respect to the plasma potential, the physically relevant reference potential. In some systems, however, the substrate cannot be biased because it is hard grounded, for example if the substrate holder is serviced by a robot. In order to make use of the benefits bias offers, one may bias the plasma positively, as opposed to negatively biasing the substrate (plasma bias [219]). This is practically done by biasing the anode of the otherwise floating plasma source (incl. its power supply).

\section{Plasma filtering for pulsed cathodic arcs and for HiPIMS}

As already mentioned in the section on cathodic arc plasma generation, the application of cathodic arc plasmas is greatly limited by the presence of macroparticles. Many attempts have been made to address this issue, and the most widely implemented solution is the use of a curved magnetic filter $[1,220]$. Such arc plasma filtering was originally developed in the 1970 s in Kharkov, then Soviet Union, by Aksenov, Belous, Khoroshikh, Padalka, and others [221, 222]; their group continued to contribute to the field for over three decades, see for example [223-226].

Plasma filtering is based on a combined magnetic and electric mechanism $[224,227,228]$. A typical magnetic field strength in a plasma filter is of the order $0.1 \mathrm{~T}$, which readily causes electron magnetization while ions are hardly affected. "Magnetization" implies here that the electron gyration radius is much smaller than the inner radius of the filter. In contrast, the ion gyration radius is usually large so that ions could not complete the gyration motion. However, ions are transported through the filter because the electrons setup a sufficiently strong radial electric field (Fig. 19). 
(FIGURE 19)

The idea of filtering or guiding plasma can be applied to HiPIMS plasmas as well. In normal operation, HiPIMS is a sputtering process, hence does not produce macroparticles. However, arcing [229] does occur, and filtering could be added if one wanted to produce films of higher quality [230]. Guiding of HiPIMS plasmas was demonstrated by Bohlmark and coworkers [231] primarily with the intent to control and enhance the flow of ions to desired locations on the substrate.

Filtering of plasma could be used not only to remove macroparticles but also negative ions [232]. As the guiding magnetic coil has features of a plasma lens [233, 234], its optics is designed to transport positive ions through the radial electrical field (Fig. 20). Negative ions are pushed out of the filter by the same radial electric field. The issue of negative ions is considered in the next subsection.

(FIGURE 20)

\section{Negative ions in cathodic arcs and HiPIMS}

Electronegative gases such as $\mathrm{O}_{2}, \mathrm{~F}_{2}$, and $\mathrm{Cl}_{2}$ form readily negative ions by electron attachment and dissociation. The following discussion is limited to oxygen and related oxides due to their practical relevance. Studying $\mathrm{Nb}, \mathrm{Ta}, \mathrm{Zr}$, and $\mathrm{Hf}$ sputtering in an $\mathrm{Ar} / \mathrm{O}_{2}$ atmosphere, Mráz and Schneider [235] concluded that the evolution of the crystalline structure of transition metal oxide thin films may depend on the presence of $\mathrm{O}^{-}$ion-bombardment-induced adatom mobility. They identified three ion populations: low, medium, and high energy ions. The low energy ions may be formed in the cathode presheath by dissociative electron attachment of oxygen and acceleration of $\mathrm{O}^{-}$by a small fraction of the target potential. The medium and the high energy ions correspond to half and the full target potential. They may leave the target $\mathrm{as}_{2}{ }^{-}$and $\mathrm{O}^{-}$ions, and are accelerated over the cathode sheath [236]. The $\mathrm{O}_{2}^{-}$may then dissociate into $\mathrm{O}$ and $\mathrm{O}^{-}$, sharing the kinetic energy between them, hence leading to an energy corresponding to half of the target potential. 
Negative ions can cause detrimental effects in growing crystalline oxide or oxynitride films when their energy is larger than the displacement energies [237]. Renucleation occurs due to ion-induced defects, and the average grain size is reduced. As a consequence, films are less conducting and more absorbing, which is of special concern for transparent conducing oxides [238-240]. Both positive and negative ions have an effect on texture and phase formation, e.g. amorphous vs. anatase vs. rutile in the case of $\mathrm{TiO}_{2}[180,241-243]$. Mass spectrometry of negative ions revealed that not only $\mathrm{O}^{-}$and $\mathrm{O}_{2}{ }^{-}$are present but also metal-containing molecular ions such as $\mathrm{TiO}_{3}{ }^{-}$in the case of reactive HiPIMS with a titanium target [244], see Fig. 21.

(FIGURE 21)

One can contrast the situation of magnetron sputtering with cathodic arc deposition, where negative ions, if present, are not accelerated to high energies because the voltages involved in arc discharges are much lower. They are generally less than $40 \mathrm{~V}$, and often as little as $20 \mathrm{~V}$, as was mentioned earlier in the cathodic arc section. Therefore, even as negative ions can be present, they are of no concern when it comes to depositing crystalline oxide films: Tay et al. [245] did not mention negative ions at all in their review on cathodic-arc-deposited oxide films. The absence of the negative ion issue is also illustrated by the deposition of transparent conducting oxide films using filtered cathodic arc deposition, which show excellent transmittance, high carrier mobility, and low resistivity [246-251].

\section{Energetic deposition using cathodic arc and HiPIMS plasmas}

This section could be an entire review on its own as there is a vast literature on the effects of ions on interface engineering and film growth (highlighting here the work by Ivan Petrov and coworkers [17]). Only some comments are given here to establish and emphasize the general connection between plasma parameters and properties of the films obtained with cathodic arcs or HiPIMS. 
As it is abundantly clear that (pulsed) cathodic arc plasmas and HiPIMS plasma have much in common but they also possess very distinct features. In both cases, energetic deposition occurs, though the ion energy distribution functions are different. In case of cathodic arc deposition of pure metal coatings (e.g. [6]), one can avoid using process gas and thus deals with vacuum arc plasmas, which usually have higher average ion energies than ions in HiPIMS plasmas. HiPIMS can also be done in vacuum but only in exceptional cases, namely when the sputter yield is very high $[157,252]$ and a means of discharge start is provided. The issue of using low pressure (typically less than $1 \mathrm{~Pa}$ ) is important for energetic deposition as collisions between the source and the substrate greatly affect the flux and energy distribution of ions actually contributing to film growth (see for example Figs. 7 and 16) [176, 253].

With gas usually present, the HiPIMS discharge excites and ionizes the process gas, which is directly related to the fact that a magnetic field is present: despite their long mean free path (long compared to the size of the target), electrons are able to cause excitation and ionization near the target. Cathodic arcs have been found to be inefficient in ionizing the process gas unless a magnetic field is present $[129,254,255]$. In this sense, cathodic arc macroparticle filters can have an important second purpose, namely providing a magnetic field that is needed to excite, dissociate (for molecular gases), and ionize the background gas. Therefore, it seems reasonable to perform a comparison of HiPIMS with filtered cathodic arcs as the amount of macroparticles on the substrate as well as gas "activation" is comparable, i.e. radical formation by dissociation (when applicable), excitation, and ionization.

Both pulsed cathodic arcs and HiPIMS plasma undergo plasma-chemical changes within each pulse, however, such effects get averaged for film growth because each pulse produces less than a monolayer of film. In the case of pulsed cathodic arcs, the ion charge states are enhanced at the beginning of each pulse $[90,256]$, which generally correlates with higher than average kinetic energies. For HiPIMS, each pulse undergoes an evolution from gas-dominated to a metal-dominated plasma, 
which is well established based on time-resolved optical emission spectroscopy $[257,258]$, mass/charge spectrometry [186, 259], spectrally resolved imaging [85, 258, 260], and last but not least by using a rotating shutter mechanism allowing us to look directly at phased ion impact on film growth [216, 217]. A direct comparison between (unfiltered) cathodic arc and HiPIMS deposition was made for the ZrN system: the HiPIMS process showed improved properties compared to the arc film which can be mainly associated with the difference in particulate contents in the films [261]. This is an example for the often-made argument that HiPIMS films are superior to cathodic arc films, namely that the particulate (a.k.a. macroparticle) content of the HiPIMS film is much lower, and therefore its quality and performance much better. For the sake of comparison, one should use a filtered arc process, however, one must acknowledge that implementing macroparticle filters is associated with a large (>50\%) loss of deposition rate. Macroparticle filtering diminishes some of the clear advantages of cathodic arc deposition: very high deposition rate, and simple, low cost operation. Filtered and unfiltered arcs show robust operation (one does not need to worry about arcing!), wide operational window for reactive deposition of compound films such as oxides and nitrides, and high effectiveness of bias due to an inherently high degree of ionization. Therefore, one cannot come to quick conclusions about the superiority of one technology over the other: both have advantages and disadvantages, and one needs to look at the specific requirements of the application as well as the economics of the process to decide which process to implement.

\section{Overview in tabular format}

Table 1 provides a comparison of cathodic arcs and HiPIMS, where emphasis is put on pulsed (and filtered) arc plasmas as they are closest in nature to HiPIMS plasmas. The intent is here to promote a big-picture comparison and it is understood that details and actual values depend on the specifics of 
the equipment used and discharge parameters selected. References are provided to help finding deeper and detailed information but no claim of completeness can be made as the literature covering the subjects counts several thousand publications.

\section{Acknowledgments}

I gratefully acknowledge the help and support by many collaborators, especially Berkeley Lab affiliates, visitors and colleagues who provided data and figures used in the review. This work was supported by the U.S. Department of Energy under Contract No. DE-AC02-05CH11231. 
Table 1. A comparison of (pulsed, filtered) cathodic arc and HiPIMS plasmas, and related deposition approaches. It is understood that parameters can vary widely depending on the specific conditions of the experiment or industrial facility. Yet, many parallels can be drawn and differences can be shown. The references are intended to provide access to further background information; and no claim is made that the list of references is comprehensive. Note that many findings for arcs predate the findings for HiPIMS.

\begin{tabular}{|c|c|c|}
\hline Property & (Pulsed, filtered) cathodic arcs & HiPIMS \\
\hline $\begin{array}{l}\text { Cathode voltage drop } \\
\text { (the difference of cathode } \\
\text { potential and plasma bulk } \\
\text { potential, the latter being } \\
\text { close to the anode potential) }\end{array}$ & $\begin{array}{l}\text { Typically } 12-28 \mathrm{~V} \text { for currents less than } 1 \mathrm{kA} \text {, } \\
\text { depending on cathode material [105, 106, 262]. } \\
\text { Such low voltage is the best "fingerprint" to } \\
\text { distinguish arcs from magnetron discharges. }\end{array}$ & $\begin{array}{l}\text { Typically } 200-1000 \mathrm{~V} \text {, depending on target material, } \\
\text { gas pressure and composition, target surface } \\
\text { conditions, and discharge current as driven by the } \\
\text { power supply }[154,257] \text {. }\end{array}$ \\
\hline $\begin{array}{l}\text { Current density at cathode } \\
\text { (target) }\end{array}$ & $\begin{array}{l}\text { Transient, fractal, up to } 10^{12} \mathrm{~A} / \mathrm{m}^{2} \text { in cathode spots } \\
{[104,263-265] \text {. }}\end{array}$ & $\begin{array}{l}\text { Varies widely, up to } 10^{6} \mathrm{~A} / \mathrm{m}^{2} \text { in ionization zones } \\
\text { [168]. Often the current density is simply normalized } \\
\text { by the entire target area, using peak current divided } \\
\text { by the target area, which gives nominal values of up }\end{array}$ \\
\hline
\end{tabular}




\begin{tabular}{|c|c|c|}
\hline & & to $10^{4} \mathrm{~A} / \mathrm{m}^{2}$. \\
\hline $\begin{array}{l}\text { Power density at the cathode } \\
\text { (target) }\end{array}$ & $\begin{array}{l}\text { Transient, fractal, up to } 10^{13} \mathrm{~W} / \mathrm{m}^{2} \text { in cathode } \\
\text { spots } \\
{[89,266,267]}\end{array}$ & $\begin{array}{l}\text { Varies widely, up to } 10^{9} \mathrm{~W} / \mathrm{m}^{2} \text { in ionization zones } \\
\text { [168]. Often the power is simply normalized by the } \\
\text { entire target area, which gives nominal values of up } \\
\text { to } 10^{7} \mathrm{~W} / \mathrm{m}^{2}[154,257,268] \text {. }\end{array}$ \\
\hline Plasma density & $\begin{array}{l}\text { Transient, in the initial explosive phase close to } \\
\text { solid state density, } 10^{26} \mathrm{~m}^{-3} \text {, and may become less } \\
\text { than } 10^{18} \mathrm{~m}^{-3} \text { in the expanded plasma near the } \\
\text { substrate }[89,269,270] .\end{array}$ & $\begin{array}{l}\text { Many of early (2000s) papers on HiPIMS point focus } \\
\text { on ionization of target atoms, which is often in the } \\
30-70 \% \text { range [271]. In most cases, both gas and } \\
\text { target ionization is important [159]. Plasma is general } \\
\text { highly non-uniform and densest in ionization zones } \\
\text { over the racetrack, up to } 10^{19} \mathrm{~m}^{-3} \text {, and about } 10^{18} \mathrm{~m}^{-3} \\
\text { in adjacent regions }[168,189,272] \text {. }\end{array}$ \\
\hline $\begin{array}{l}\text { Electron temperature or } \\
\text { energy }\end{array}$ & $\begin{array}{l}1.5 \text { to } 4.5 \mathrm{eV} \text {, depending on cathode material, in } \\
\text { the transition region from equilibrium to non- } \\
\text { equilibrium close to the cathode spot [125]. }\end{array}$ & $\begin{array}{l}\text { About } 1 \mathrm{eV} \text { plus a sharply truncated high-energy tail } \\
\text { during a pulse, with the hot electrons decreasing } \\
\text { after } \sim 100 \mu \text { s after a pulse initiation [167]. Up to } 5 \mathrm{eV} \\
\text { during the discharge, dropping to about } 1 \mathrm{eV} \text { in the } \\
\text { pulse afterglow [189]. Heated by electric field in the }\end{array}$ \\
\hline
\end{tabular}




\begin{tabular}{|c|c|c|}
\hline & & presheath [166]. \\
\hline Ion charge states & $\begin{array}{l}1+\text { to } 5+\text {, most metals have large fractions of } 2+ \\
\text { and } 3+\text { ions }[129,273] \text {, it also applies to composite } \\
\text { cathodes }[274,275] \text {. }\end{array}$ & $\begin{array}{l}\text { Mostly } 1+\text { but also a significant fraction of } 2+[181] \text {, } \\
\text { and in extreme cases } 3+\text { and } 4+[87] \text {. }\end{array}$ \\
\hline $\begin{array}{l}\text { Energies of positive ions at } \\
\text { substrate }\end{array}$ & $\begin{array}{l}\text { In plasma: most likely energy is about from } 20 \mathrm{eV} \\
\text { for light ions (like C ions) to about } 120 \mathrm{eV} \text { for } \\
\text { refractory metals (like W ions) [129]. Ion energy } \\
\text { distributions (incl. all charge states) show one } \\
\text { peak [130, 131]. lon energies are further enhanced } \\
\text { by acceleration in the sheath of the substrate. }\end{array}$ & $\begin{array}{l}\text { Ion energy distributions show three significant } \\
\text { features: a thermal peak at very low energy }(\sim 1 \mathrm{eV}) \text {, } \\
\text { a broad non-Thompson peak at typically several } 10 \\
\text { eV, which may be assigned to ion acceleration from } \\
\text { ionization zones }[169,174] \text {, and an energy tail from } \\
\text { sputtering cascade (Thompson distribution [276]) } \\
\text { [277]. }\end{array}$ \\
\hline Energies of negative ions & $\begin{array}{l}\text { Low energy only ( }<40 \mathrm{eV} \text {, due to the absence of } \\
\text { high voltages). }\end{array}$ & $\begin{array}{l}\text { Energy distributions have peaks related to the full } \\
\text { and half target potential [236]; besides } O^{-} \text {negative } \\
\text { molecular ions are observed [242]. }\end{array}$ \\
\hline $\begin{array}{l}\text { Macroparticle contamination } \\
\text { and plasma filtering }\end{array}$ & $\begin{array}{l}\text { Contamination is severe without filtering, less with } \\
\text { poisoned cathodes (e.g. surface oxidized), } \\
\text { acceptable for some applications like hard }\end{array}$ & $\begin{array}{l}\text { No macroparticle contamination in the absence of } \\
\text { arcing, however, arcing does occur and film quality } \\
\text { depends on current levels, target material, target }\end{array}$ \\
\hline
\end{tabular}




\begin{tabular}{|c|c|c|}
\hline & $\begin{array}{l}\text { coatings on tools }[278,279] \text {; optical and other } \\
\text { applications require filtered arcs }[245,280,281] \text {. }\end{array}$ & $\begin{array}{l}\text { history, and on the properties of the arc suppression } \\
\text { system }[229,282-284] \text {. }\end{array}$ \\
\hline Species-selective bias & $\begin{array}{l}\text { Using two or more cathodes, bias is applied } \\
\text { depending on which plasma arrives at the target } \\
\text { at a given time }[209,213] \text {. }\end{array}$ & $\begin{array}{l}\text { Demonstrated as bias pulses are phased with HiPIMS } \\
\text { pulses to make use of the changing plasma } \\
\text { composition within each pulse [218]. }\end{array}$ \\
\hline $\begin{array}{l}\text { High bias for ion etch and } \\
\text { surface preparation }\end{array}$ & $\begin{array}{l}\text { Etch demonstrated using unfiltered arc plasma } \\
\text { [195], and using filtered arc plasma [197]. }\end{array}$ & Etch demonstrated using HiPIMS plasma $[77,198]$. \\
\hline Deposition in vacuum & $\begin{array}{l}\text { Common, e.g. [6], known as vacuum arcs }[88,91] \text {; } \\
\text { most measurements of charge states and ion } \\
\text { energies are done in vacuum to eliminate the } \\
\text { effects of gas }[1,88] \text {. }\end{array}$ & $\begin{array}{l}\text { Unusual but possible for materials of very high self- } \\
\text { sputter yields }[157,158,252] \text {. }\end{array}$ \\
\hline $\begin{array}{l}\text { Deposition in reactive gas } \\
\text { atmospheres }\end{array}$ & $\begin{array}{l}\text { Widely practiced for the deposition of hard, } \\
\text { decorative, and protective coatings, often based } \\
\text { on nitrides }[285,286] \text {, carbides [287], oxides [ } 247 \text {, } \\
288] \text {, oxynitrides [289], and sometimes complex } \\
\text { compounds }[138,290] \text {. }\end{array}$ & $\begin{array}{l}\text { Widely practiced for compound films, including } \\
\text { nitrides [77, 199, 291-293], carbides [294], oxides } \\
\text { [277, 295-302], and more complex compounds [303, } \\
304] \text {. }\end{array}$ \\
\hline Deposition rates & Very high deposition rates by standards of physical & In most but not all cases notably lower (several $10 \%$ \\
\hline
\end{tabular}




\begin{tabular}{|c|c|c|}
\hline & $\begin{array}{l}\text { vapor deposition, can be as high as } 15-20 \mathrm{~nm} / \mathrm{s} \text { for } \\
\text { unfiltered process. Filtering reduces rates typically } \\
\text { by } 3 / 4 \text {. Example of a high rate filtered arc process } \\
\text { is AZO: about } 4-5 \mathrm{~nm} / \mathrm{s} \text { [247]; and for } \mathrm{Al}_{2} \mathrm{O}_{3}: 2 \\
\mathrm{~nm} / \mathrm{s} \text { [305] and } 3-4 \mathrm{~nm} / \mathrm{s} \text { [306]. For pulsed } \\
\text { systems, using high currents ( } 1 \mathrm{kA}) \text { : about } 1 \\
\text { nm/pulse [307], or } 3-5 \mathrm{~nm} / \mathrm{s} \text { for filtered high } \\
\text { current arc with a graphite cathode [308]. }\end{array}$ & $\begin{array}{l}\text { lower) compared to the deposition rates of dc } \\
\text { sputtering at the same power [309], primarily due to } \\
\text { return effect of ionized sputtered material, but also } \\
\text { affected by a host of other changes [310] including } \\
\text { the energy dependence of the sputter yield [311]. } \\
\text { About } 3 \mathrm{~nm} / \mathrm{s} \text { for Cr compound films using MPP } \\
\text { [312]. Under selected conditions, in the transition } \\
\text { region of reactive sputtering, deposition rates can be } \\
\text { higher than the dc rate [313]. }\end{array}$ \\
\hline Use of more than one source & $\begin{array}{l}\text { More than one arc source is often used to increase } \\
\text { the area to be coated and/or to tune film } \\
\text { composition [314, 315]; using different cathodes, } \\
\text { co-deposition can be used for doping [213], or } \\
\text { leads to embedded nanoparticle formation [316], } \\
\text { alloy-compounds [248], multilayers [317] or } \\
\text { nanolaminates [318, 319]. }\end{array}$ & $\begin{array}{l}\text { Magnetrons are often used in dual-magnetron } \\
\text { configuration [320-322] to address the "disappearing } \\
\text { anode" problem in reactive deposition; the principle } \\
\text { has been extended to HiPIMS [323-325]. To increase } \\
\text { the HiPIMS deposition rate, a HiPIMS-rf hybrid } \\
\text { scheme can be employed [326]. Using different } \\
\text { targets, co-deposition can lead to alloy-compounds, }\end{array}$ \\
\hline
\end{tabular}




\begin{tabular}{|c|c|c|}
\hline & & superlattices [327] or nanolaminates $[328,329]$. \\
\hline $\begin{array}{l}\text { Scalability, cost, and other } \\
\text { economic considerations }\end{array}$ & $\begin{array}{l}\text { Unfiltered reactive cathodic arc deposition is } \\
\text { widely used in industrial batch coaters, and rarely } \\
\text { in in-line coaters, likely for uniformity concerns } \\
\text { [278]. Due to high deposition rate, a preferred } \\
\text { economical process when macroparticles can be } \\
\text { tolerated. }\end{array}$ & $\begin{array}{l}\text { Likely to be an economical success where the } \\
\text { enhanced coating quality is demonstrated and } \\
\text { needed; scaling to target sizes of } \sim 1 \mathrm{~m} \text { length } \\
\text { demonstrated, with peak power of up to } 8 \mathrm{MW} \text { [301, } \\
\text { 330-332]. }\end{array}$ \\
\hline
\end{tabular}




\section{Figure Captions}

Fig. 1 Film deposition apparatus showing arc plasma generation and substrate bias, adapted from Burkhardt and Reinecke's patent [23], filed in 1937.

Fig. 2 Early ion plating apparatus by Mattox, where vapor ionization and ion acceleration are accomplished by a discharge; the substrate is the cathode (adapted from Mattox' review [33])

Fig. 3 Open-shutter photograph, taken through a vacuum chamber window, of a flange-mounted cathodic arc source and mirror placed inside the chamber. The discharge was a cathodic arc discharge in vacuum (vacuum arc) using a graphite cathode. The plasma of vacuum arc appears relatively dim as excitation collisions far from the cathode spot are rare. Hot macroparticles are ejected from the explosive processes at the cathode spot, and easily visible by the bright straight lines. Note that macroparticles tend to be reflected from solid surfaces, an issue to be addressed when filtering cathodic arc plasmas.

Fig. 4 Cathodic vacuum arc erosion craters: in this example, the cathode was not metallically clean as evident by the spread of craters. The craters appear in a straight band since a magnetic field caused preferred ignition in one direction (a.k.a. magnetically steered arc). Image taken in the late 1970s, courtesy of B. Jüttner, Berlin.

Fig. 5 Electron micrograph of a surface of a titanium radio-frequency cavity, subjected to very high electric fields (original image from CERN, published in [121]).

Fig. 6 Illustration of the Cohesive Energy Rule for cathodic arcs, showing cohesive energy, mean ion charge state, and the most likely ion energy for many elemental cathodes (from [90]).

Fig. 7 Ion energy distribution function of a cathodic arc with an aluminum cathode as a function of the product of distance from the cathode and pressure of pure argon (After Aitser et al. [333]). 
Fig. 8 Open-shutter photograph of a pulsed high current cathodic vacuum arc: the central electrode was the trigger, and the mesh is the anode of the discharge. Several arc spots start at the trigger pin and move away driven by the magnetic field (image from the 1980s, courtesy of B. Jüttner, Berlin).

Fig. 9 Plasma potential (left) and derived electric field (right) for a 3" Nb HiPIMS-discharge in 0.26 Pa argon, measured with an emissive probe. The probe was systematically moved after 100 pulses were measured: each measurement location is indicated by a black dot or arrow. Adapted from [143].

Fig. 10 Schematic representation of ion and atom fluxes in magnetron sputtering operated at high power, when both gas and target atoms are ionized. The right side describes the impact of gas ions on the target, causing emission of secondary electrons and sputtering of target atoms (yield $\gamma$ ), and a return of the gas ions in the form of (neutralized) atoms unless accommodated with a probability $\delta$. Both target and gas atoms can then be ionized (probability $\alpha$ ) and return to the target (probability $\beta$ ). The indices t and g refer to 'target' and 'gas' (from [159]).

Fig. 11 Spectrally resolved images of ionization zones, obtained by using a fast camera with image intensifier (PIMAX by Princeton Instruments) in conjunction with a spectral filter matched to selected emission lines of atoms or ions, as indicated. Adapted from [170].

Fig. 12 lonization zone over a niobium target sputtered in argon (upper image), with the proposed potential hump (lower image); the electric field and net space charge were calculated using the first and second derivative of the potential. Adapted from [169].

Fig. 13 Energy distribution functions for $\mathrm{Ti}^{+}$(top) and $\mathrm{O}^{+}$(bottom) HiPIMS discharges; distribution measured for dc discharge are given for comparison. From [172].

Fig. 14 IEDFs measured in HiPIMS along the side of the magnetron for (a) $\mathrm{Ar}^{+}$, (b) $\mathrm{Ar}^{2+}$, (c) $\mathrm{Nb}^{+}$and (d) $\mathrm{Nb}^{2+}$. From [174]. 
Fig. 15 HiPIMS with 3" aluminum target in argon, peak current $100 \mathrm{~A}$; the images show side-on views of the light from ions as recorded through a spectral filter (top: argon ions, bottom: aluminum ions); each image is from a different discharge pulse as the PIMAX camera took one image per pulse, each with an exposure time of 150 ns. Adapted from [170].

Fig. $16 \mathrm{Nb}$ HiPIMS discharge in argon at different pressures: the measurements show the timedependent ion saturation probe currents for $0.13,1.75$, and $4 \mathrm{~Pa}$ at 6 and $14 \mathrm{~cm}$ distance from the target, for different collection angles. Note that the current scales for top row ( $6 \mathrm{~cm}$ distance) and bottom row (14 cm distance) are different (adapted from [176]).

Fig. 17 Two-segmented burst of short HiPIMS pulses: here, in this example, the first segment was done with $3 \mu \mathrm{s}$ on and $40 \mu \mathrm{s}$ off, while in the second segment the pulses were $12 \mu \mathrm{s}$ on and $6 \mu \mathrm{s}$ off. As a consequence, the discharge current increases. From [181].

Fig. 18 One of several combinations using pulse arc plasma and pulsed bias: here, relatively long pulses are used and a burst of bias pulses is applied when the plasma is present. The duty cycle of the bias determines the ratio of ion implantation (or more often subplantation, given the typical bias voltage of several $100 \mathrm{~V}$ ) and deposition. After [194].

Fig. 19 View to an open-coil, curved cathodic arc filter for the deposition of high quality films. Here with a $30 \mathrm{~A}$ dc-arc source, zinc cathode, in oxygen background to form $\mathrm{ZnO}$ (or Al-doped ZnO (AZO) depending on the Al-content of the zinc cathode).

Fig. 20 HiPIMS plasma transported through a straight filter from the magnetron on the right to the heated substrate holder on the left, with the intent to remove energetic negative oxygen ions that are detrimental to the obtaining high quality oxide films, here AZO as a transparent conducting film (from [232]). 
Fig. 21 lon energy distributions of $\mathrm{O}^{-}, \mathrm{O}^{-2}, \mathrm{TiO}^{-}, \mathrm{TiO}^{-2}$ and $\mathrm{TiO}^{-3}$ in reactive HiPIMS of $\mathrm{Ti}$ in an 80:20 argon/oxygen mixture. The average on-phase absolute target potential was approximately $-500 \mathrm{~V}$. From [242]. 




Fig. 1 


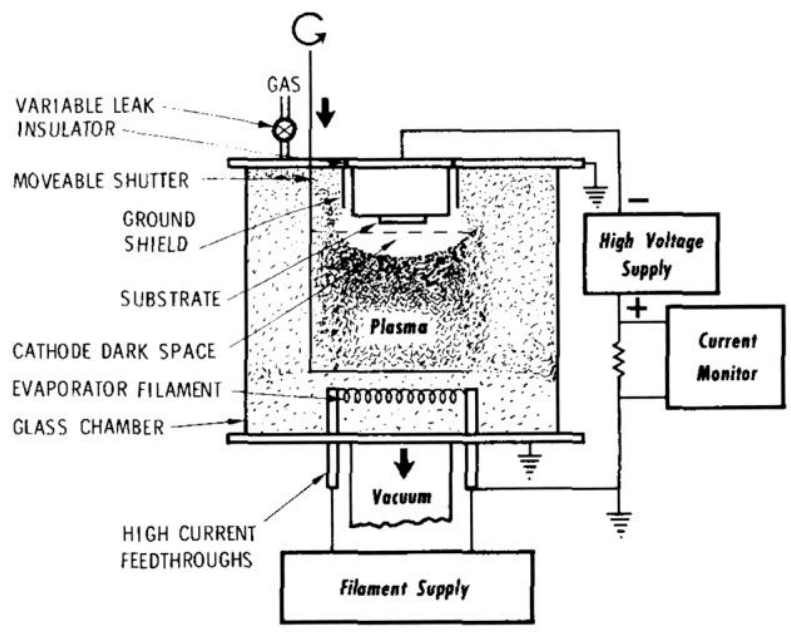

Fig. 2 




Fig. 3 




Fig. 4 


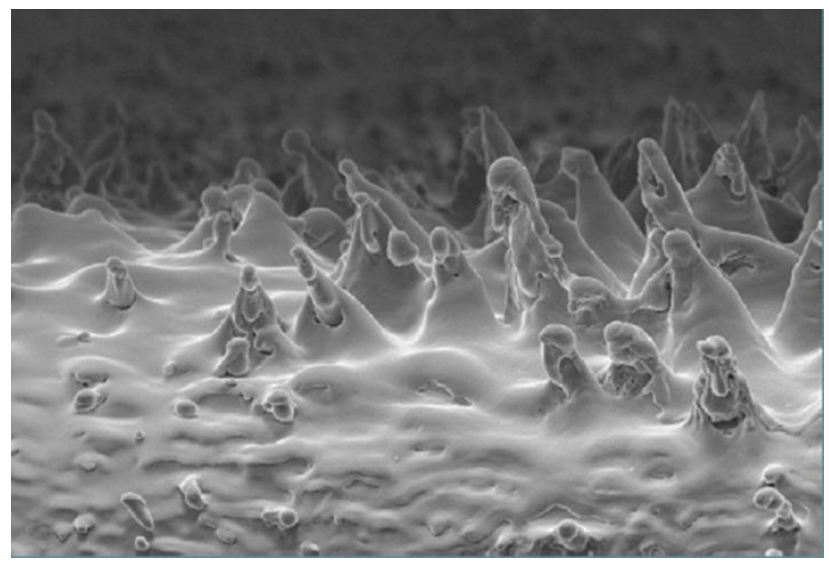

Fig. 5 




Fig. 6 


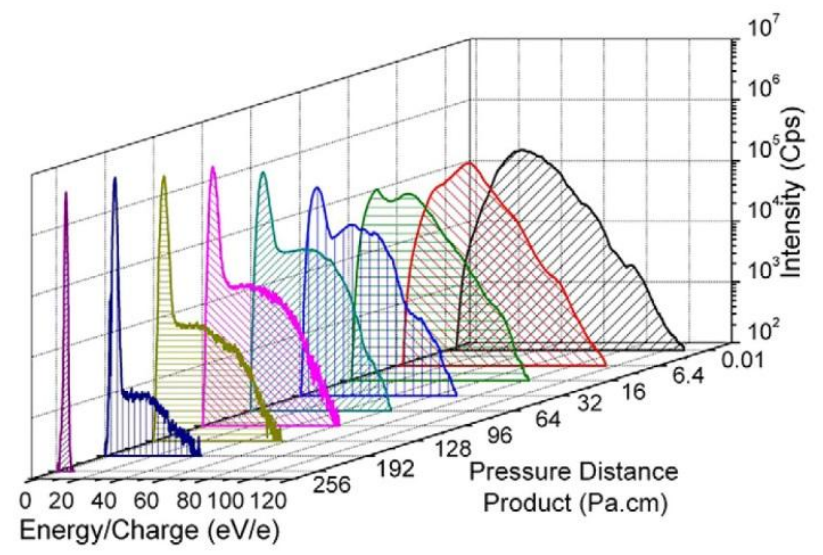

Fig. 7 


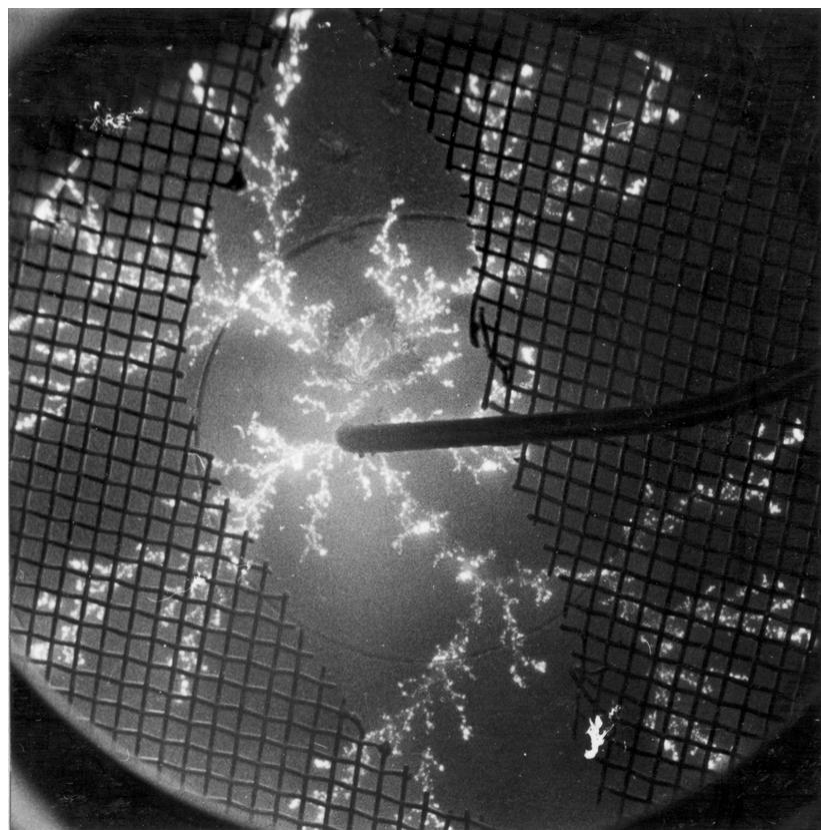

Fig. 8 


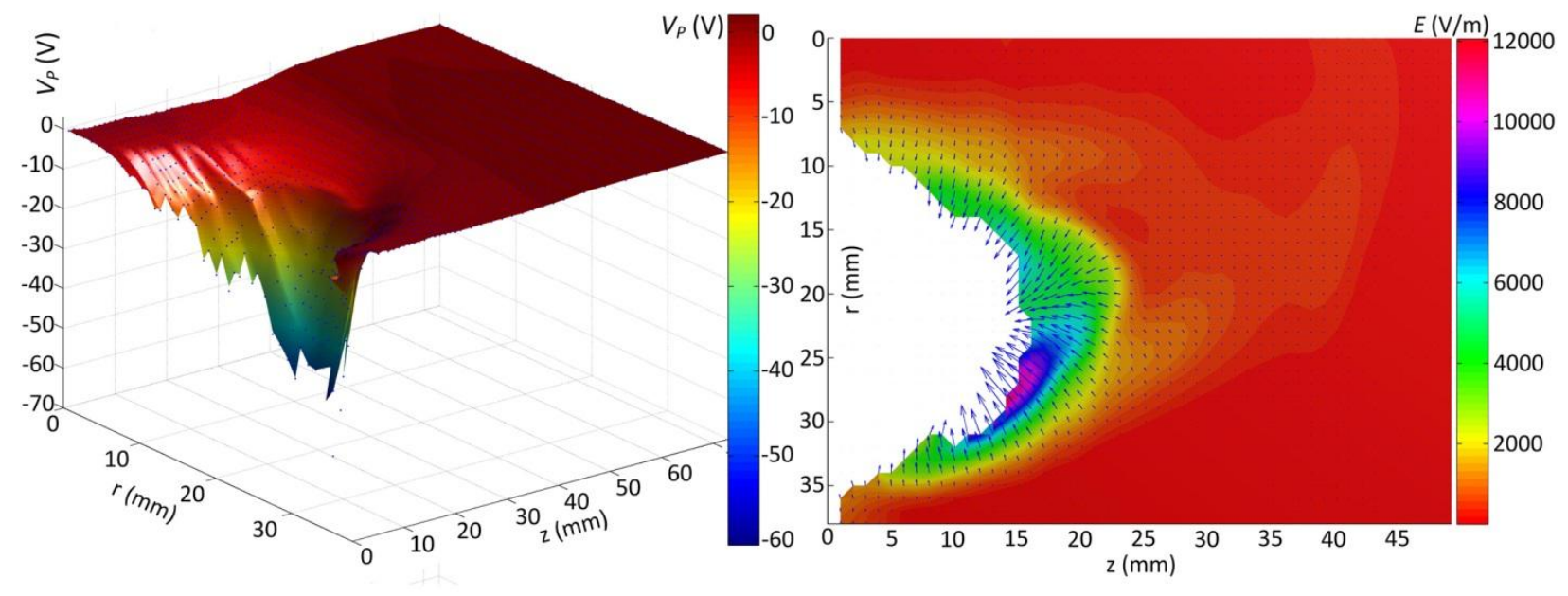

Fig. 9 


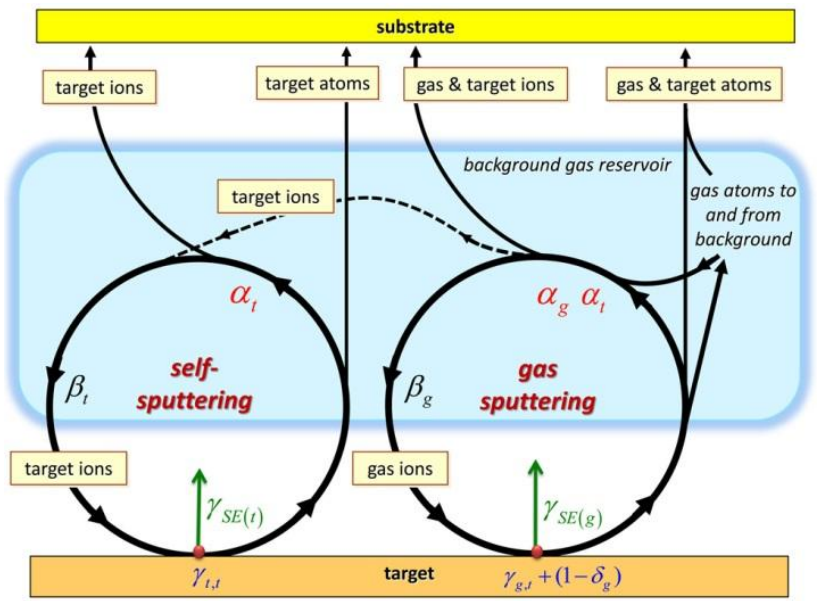

Fig. 10 


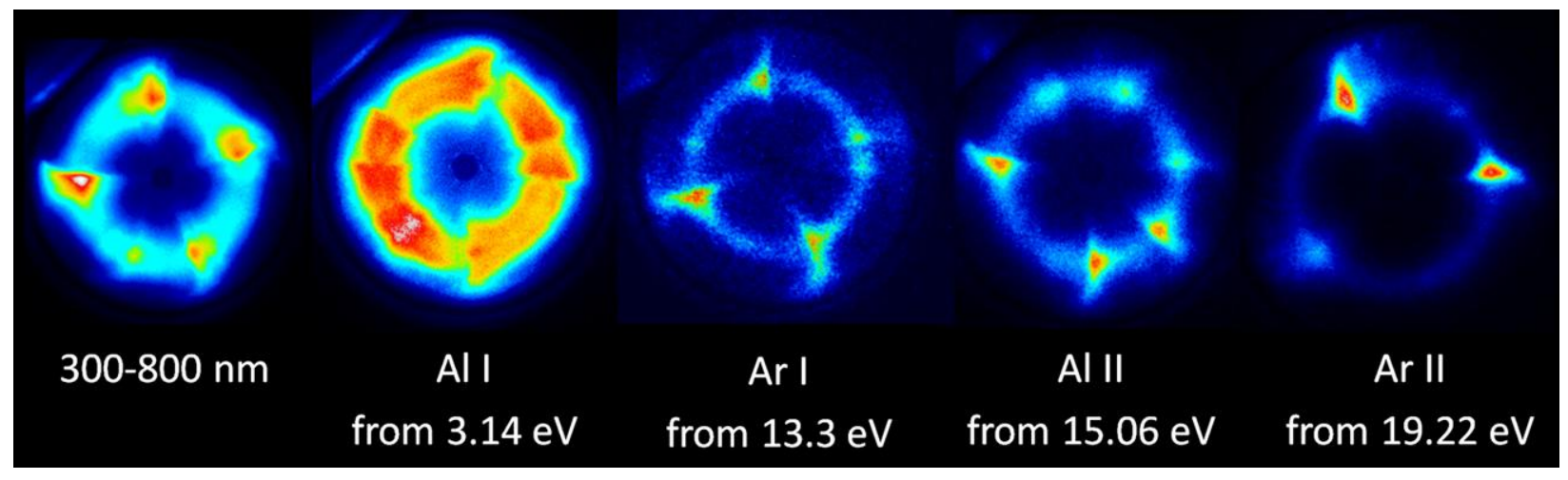

Fig. 11 



Fig. 12 



Fig. 13 

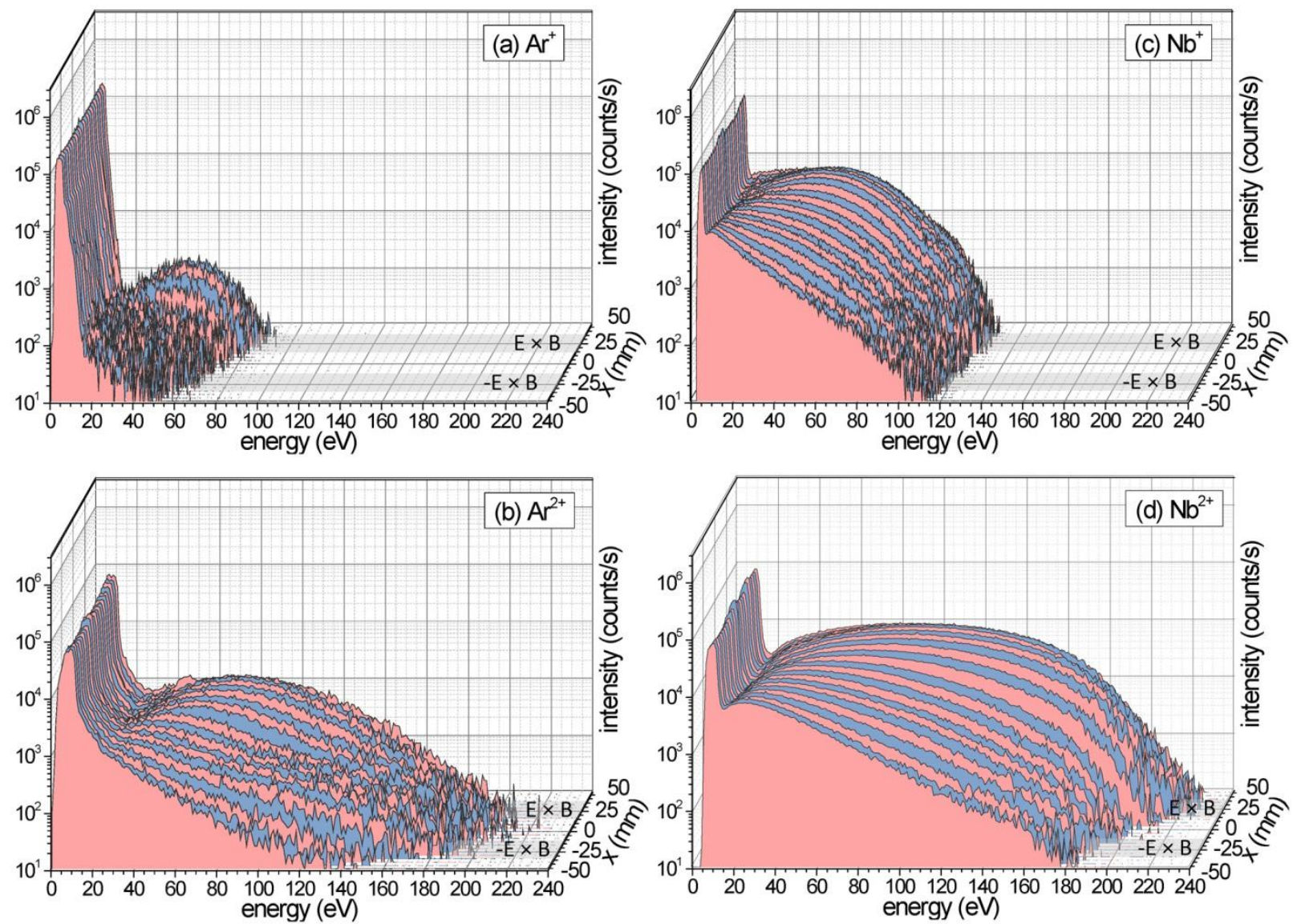

Fig. 14 


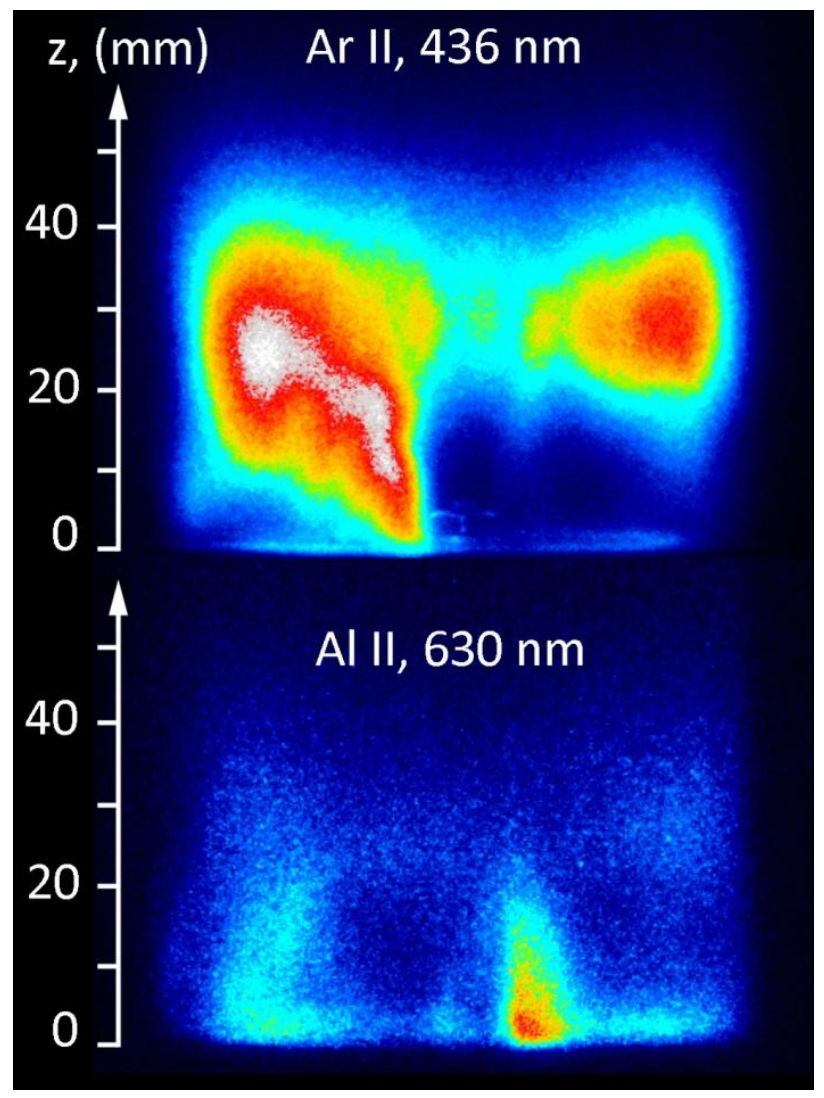

Fig. 15 



Fig. 16 


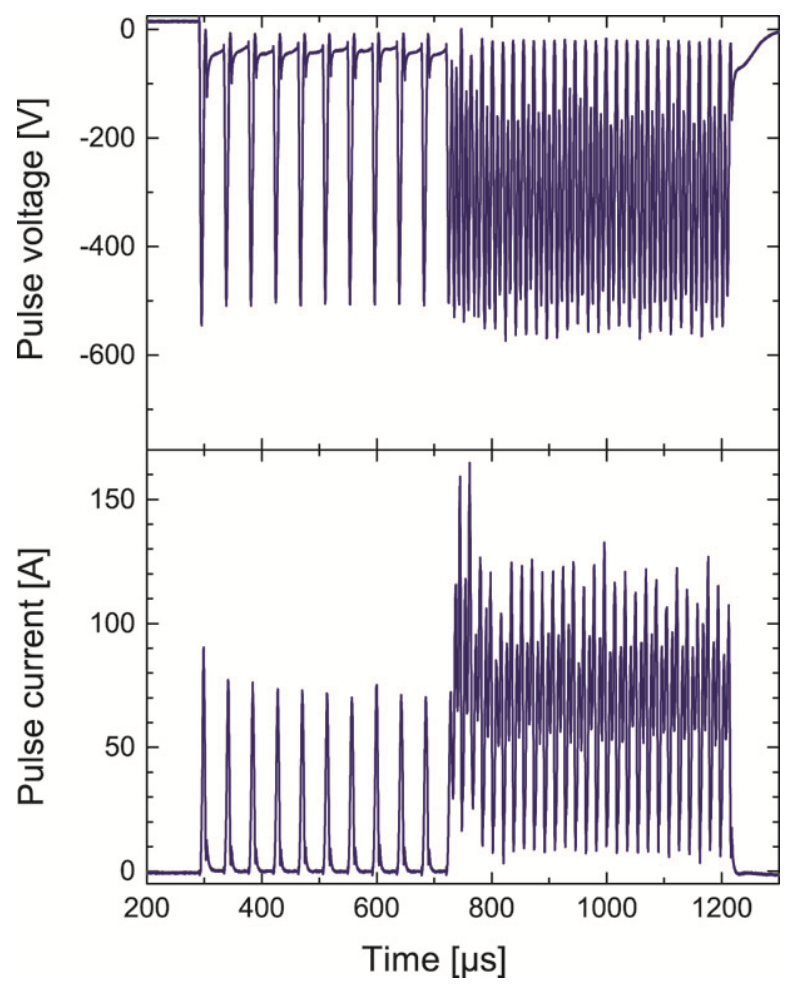

Fig. 17 


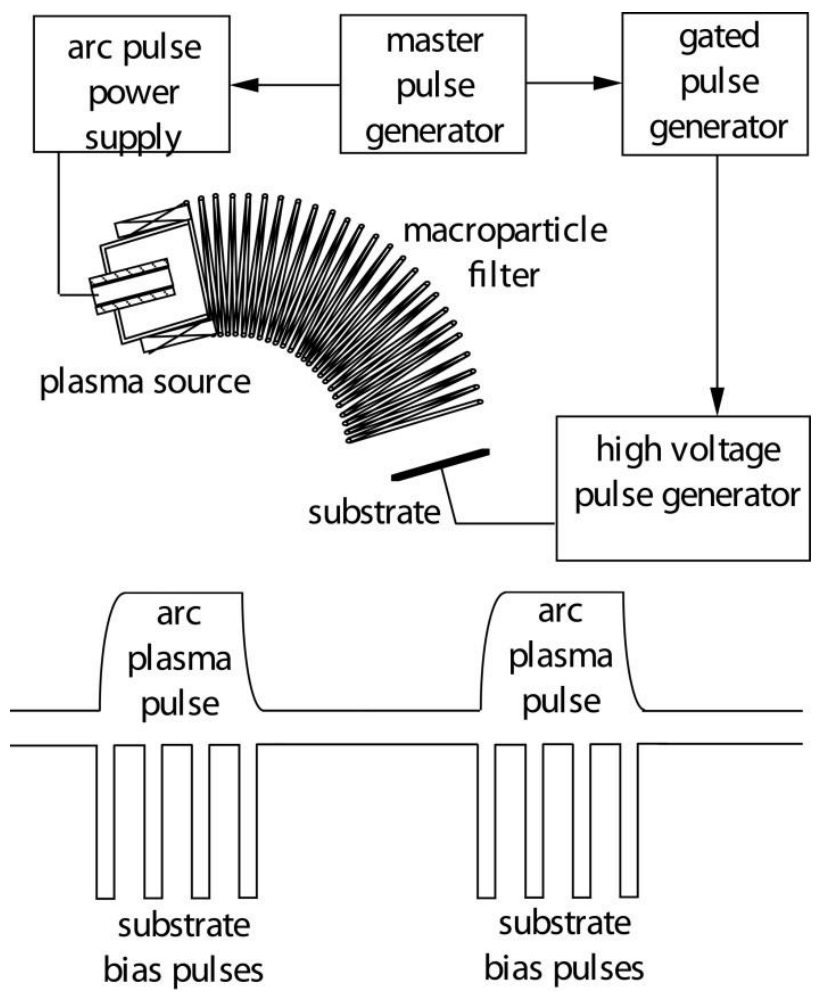

Fig. 18 


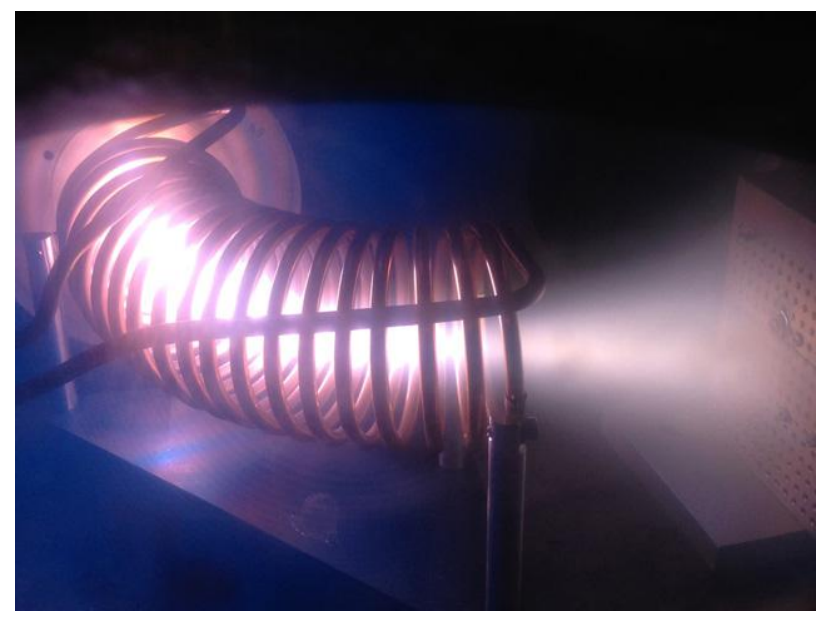

Fig. 19 


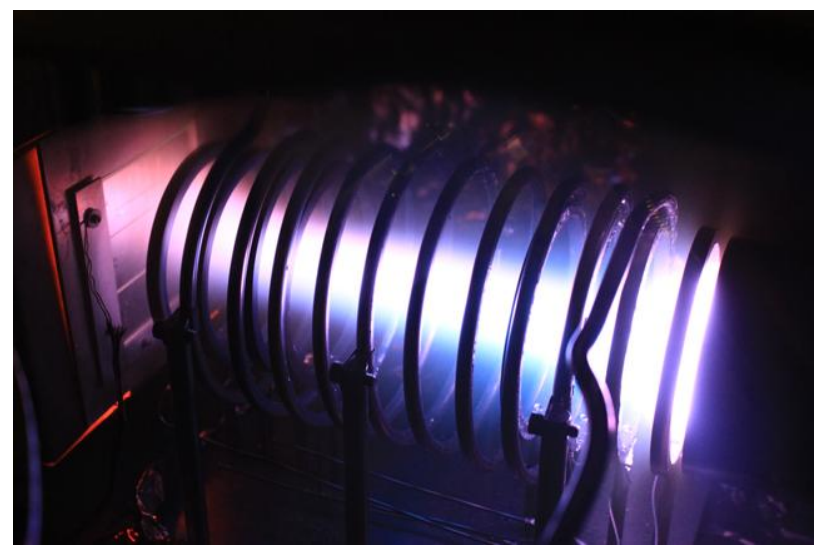

Fig. 20 




Fig. 21 


\section{References}

[1] A. Anders, Cathodic Arcs: From Fractal Spots to Energetic Condensation. New York: Springer, 2008.

[2] J. S. Colligon, "Energetic condensation: processes, properties, and products," J. Vac. Sci. Technol. A, vol. 13, pp. 1649-1657, 1995.

[3] D. R. McKenzie and M. M. M. Bilek, "Thermodynamic theory for preferred orientation in materials prepared by energetic condensation," Thin Solid Films, vol. 382, pp. 280-287, 2001.

[4] O. R. Monteiro, "Thin film synthesis by energetic condensation," Annu. Rev. Mater. Sci., vol. 31, pp. 111-137, 2001.

[5] A. Anders, "Observation of self-sputtering in energetic condensation of metal ions," Appl. Phys. Lett., vol. 85, pp. 6137-6139, 2004.

[6] M. Krishnan, E. Valderrama, C. James, X. Zhao, J. Spradlin, A. M. V. Feliciano, L. Phillips, C. E. Reece, K. Seo, and Z. H. Sung, "Energetic condensation growth of Nb thin films," Physical Review Special Topics - Accelerators and Beams, vol. 15, p. 032001, 2012.

[7] X. Zhao, A. M. Valente-Feliciano, C. Xu, R. L. Geng, L. Phillips, C. E. Reece, K. Seo, R. Crooks, M. Krishnan, A. Gerhan, B. Bures, K. W. Elliott, and J. Wright, "Large crystal grain niobium thin films deposited by energetic condensation in vacuum arc," J. Vacuum Sci. Technol. A, vol. 27, pp. 620625, 2009.

[8] V. E. Strel'nitskii, V. G. Padalka, and S. I. Vakula, "Properties of the diamond-like carbon film produced by the condensation of a plasma stream with an rf potential," Sov. Phys.-Techn. Phys., vol. 23, pp. 222-224, 1978.

[9] A. Anders, "Energetic deposition using filtered cathodic arc plasmas," Vacuum, vol. 67, pp. 673686, 2002.

[10] G. Wu, H. L. Phillips, and R. M. Sundelin, "Energetic deposition of niobium thin film by ECRplasma," J. Vac. Sci. Technol. A, vol. 21, pp. 842-845, 2003.

[11] C. C. Klepper, O. R. Monteiro, E. P. Carlson, and M. D. Keitz, "Energetic deposition of ${ }^{10} B$ on high aspect ratio trenches for neutron detectors," J. Vacuum Sci. Technol. B, vol. 27, pp. L14-L17, 2009.

[12] A. Moafi, D. W. M. Lau, A. Z. Sadek, J. G. Partridge, D. R. McKenzie, and D. G. McCulloch, "Energetic deposition of carbon in a cathodic vacuum arc with a biased mesh," J. Appl. Phys., vol. 109, p. 073309, 2011. 
[13] H. Wu and A. Anders, "Energetic deposition of metal ions: Observation of self-sputtering and limited sticking for off-normal angles of incidence," J. Phys. D: Appl. Phys., vol. 43, p. 065206, 2010.

[14] A. Anders, "Atomic scale heating in cathodic arc plasma deposition," Appl. Phys. Lett., vol. 80, pp. 1100-1102, 2002.

[15] A. R. Gonzalez-Elipe and J. M. Sanz, Low energy ion assisted film growth. Singapore: Imperial College Press and World Scientific, 2003.

[16] J. E. Greene, "Nucleation, film growth, and microstructural evolution," in Handbook of Deposition Technologies for Films and Coatings, R. F. Bunshah, Ed., 2nd ed Westwood, NJ: Noyes, 1994, pp. 681-739.

[17] I. Petrov, P. B. Barna, L. Hultman, and J. E. Greene, "Microstructural evolution during film growth," J. Vac. Sci. Technol. A, vol. 21, pp. S117-S128, 2003.

[18] J. Priestley, "Experiments in which rings, consisting of all the prismatic colours, where made by electrical explosions on the surface of metals," in The History and Present State of Electricity, vol. II, ed London, 1775, pp. 329-335.

[19] W. R. Grove, "On some anomalous cases of electrical decomposition," Phil. Mag., pp. 203-211, 1853.

[20] A. W. Wright, "On the production of transparent films by the electrical discharge in exhausted tubes," Am. J. Science \& Arts, 3rd Series, vol. 13, pp. 49-55, 1877.

[21] T. A. Edison, "Art of plating one material with another," U.S. 526,147, 1894.

[22] W. R. Grove, "On the electro-chemical polarity of gases," Phil. Mag., vol. 4, pp. 498-515, 1852.

[23] W. Burkhardt and R. Reinecke, "Method of coating articles by vaporized coating materials," US Patent 2,157,478, 1939.

[24] B. Berghaus, "Improvements in and relating to the coating of articles by means of thermally vaporised material," GB Patent 510,993, 1939.

[25] B. Berghaus and W. Burkhardt, "Coatings of articles by cathode disintegration," US Patent 2,305,758, 1942.

[26] R. W. Ditchburn, "The deposition of sputtered films," Proc. Royal Society of London. Series A, vol. 141, pp. 169-188, 1933.

[27] R. S. Freund, R. C. Wetzel, R. J. Shul, and T. R. Hayes, "Cross-section measurements for electron impact ionization of atoms," Phys. Rev. A, vol. 41, pp. 3575-3595, 1990. 
[28] H. Tawara and T. Kato, "Total and partial ionization cross sections of atoms and ions by electron impact," Atomic Data and Nuclear Data Tables, vol. 36, pp. 167-353, 1987.

[29] B. Tsipinyuk, A. Bekkerman, and E. Kolodney, "Binary encounter models for electron ionization of atoms: A one parameter expression for electron energy dependent $(E<200 \mathrm{eV})$ single ionization cross section," Int. J. Mass Spectrometry, vol. 328-329, pp. 2-16, 2012.

[30] A. J. T. Holmes, "Transitions between thermionic and vapour arc modes," J. Phys. D: Appl. Phys., vol. 9, pp. 537-545, 1976.

[31] S. Anders and A. Anders, "On modes of arc cathode operation," IEEE Trans. Plasma Sci., vol. 19, pp. 20-24, 1991.

[32] D. M. Mattox, "Film deposition using accelerated ions," Sandia Corporation, Albuquerque Report SC-DR-281-63, 1963.

[33] D. M. Mattox, "Fundamentals of ion plating," J. Vac. Sci. Technol., vol. 10, pp. 47-52, 1973.

[34] H. J. Hamilton, "Apparatus for depositing ionized electron beam evaporated material on a negatively biased substrate," US 3,404,084, 1968.

[35] D. M. Mattox, "Apparatus for coating a cathodically biased substrate from plasma of ionized coating material," US Patent 3,329,601, 1967.

[36] E. Kay, "Method of cathode sputtering including cleaning by ion bombardment wherein an article to be coated is subject to canal rays," US Patent 3,341,442, 1967.

[37] I. I. Aksenov, V. A. Belous, V. G. Padalka, and V. M. Khoroshikh, "Producing coatings with aluminium oxide base from separated flow of vacuum arc plasma," Fizika i Khimiya Obrabotki Materialov (Physics and Chemistry of Materials Processing), vol. No. 6, pp. 89-93, 1977.

[38] I. M. Aksenov, V. G. Bren', V. V. Kunchenko, V. V. Lokoshko, V. A. Osipov, V. G. Padalka, and O. I. Soprykin, "Coatings based on nitides of the steel Kh18N10T, obtained by the KIB method (in Russ.)," Fizika i Khimiya Obrabotki Materialov (Physics and Chemistry of Materials Processing), vol. No. 5, pp. 100-104, 1977.

[39] M. S. P. Lucas, J. H. A. Owen, W. C. Stewart, and C. R. Vail, "Vacuum-arc evaporation of refractory metals," Rev. Sci. Instrum., vol. 32, pp. 203-204, 1961.

[40] A. A. Snaper, "Arc deposition process and apparatus," US 3,625,848, 1971.

[41] H. J. Scheibe, B. Schultrich, H. Ziegele, and P. Siemroth, "Deposition of superhard amorphous carbon films by pulsed arc sources," IEEE Trans. Plasma Sci., vol. 25, pp. 685-688, 1997.

[42] P. Siemroth, T. Schülke, and T. Witke, "High-current arc - a new source for high-rate deposition," Surf. Coat. Technol., vol. 68, pp. 314-319, 1994. 
[43] I. G. Brown, X. Godechot, and K. M. Yu, "Novel metal ion surface modification technique," Appl. Phys. Lett., vol. 58, pp. 1392-1394, 1991.

[44] I. G. Brown, A. Anders, S. Anders, M. R. Dickinson, I. C. Ivanov, R. A. MacGill, X. Y. Yao, and K.-M. $\mathrm{Yu}$, "Plasma synthesis of metallic and composite thin films with atomically mixed substrate bonding," Nucl. Instrum. Meth. Phys. Res. B, vol. 80/81, pp. 1281-1287, 1993.

[45] R. Behrisch and W. Eckstein, Eds., Sputtering by Particle Bombardment. Berlin: Springer, 2007.

[46] T. Ono, T. Kenmotsu, and T. Muranoto, "Simulation of the Sputtering Process," in Reactive Sputter Deposition, D. Depla and S. Mahieu, Eds., ed Berlin: Springer, 2008, pp. 1-42.

[47] H. S. Norrie, Ruhmkorff Induction Coils, Their Construction, Operation and Application. New York: Spon \& Chamberlain, 1896.

[48] F. M. Penning, "Coating by cathode disintegration," USA Patent US 2,146,025, 1939.

[49] J. S. Chapin, "The planar magnetron," Vacuum Technology, pp. 37-38, 1974.

[50] J. S. Chapin, "Sputtering process and apparatus," US 4,166,018, 1979.

[51] P. J. Clarke, "Sputtering Apparatus," US Patent 3,711,398, 1973.

[52] J. A. Thornton, "Magnetron sputtering: basic physics and application to cylindrical magnetrons," J. Vac. Sci. Technol., vol. 15, pp. 171-177, 1978.

[53] A. S. Penfold and J. A. Thornton, "Electrode type glow discharge," US Patent 3,884,793, 1975.

[54] A. S. Penfold, "Early days of magnetron sputtering--an enigma," Thin Solid Films, vol. 171, pp. 99108, 1989.

[55] D. M. Mattox, The History of Vacuum Coating Technology. Albuquerque: Society of Vacuum Coaters, 2002.

[56] G. Bräuer, J. Szczyrbowski, and G. Teschner, "Mid frequency sputtering-a novel tool for large area coating," Surf. Coat. Technol., vol. 94, pp. 658-662, 1997.

[57] B. Window and N. Savvides, "Charged particle fluxes from planar magnetron sputtering sources," J. Vac. Sci. Technol. A, vol. 4, pp. 196-202, 1986.

[58] A. Matthews, "Plasma-based physical vapor deposition surface engineering processes," J. Vac. Sci. Technol. A, vol. 21, pp. S224-S231, 2003.

[59] J. A. Hopwood, Ed., lonized Physical Vapor Deposition. San Diego, CA: Academic Press, 2000.

[60] C. A. Nichols, S. M. Rossnagel, and S. Hamaguchi, "Ionized physical vapor deposition of Cu for high aspect ratio damascene trench fill applications," J. Vacuum Sci. Technol. B, vol. 14, pp. 3270-3275, 1996. 
[61] S. M. Rossnagel and J. Hopwood, "Magnetron sputter deposition with high levels of metal ionization," Appl. Phys. Lett., vol. 63, pp. 3285-3287, 1993.

[62] S. M. Rossnagel and F. Qian, "Mechanism for highly ionized magnetron sputtering," J. Appl. Phys., vol. 78, pp. 758-765, 1995.

[63] R. C. Krutenat and W. R. Gesick, "Vapor deposition by liquid phase sputtering," J. Vacuum Sci. Technol., vol. 7, pp. S40-S44, 1970.

[64] S. Kadlec and J. Musil, "Low pressure magnetron sputtering and selfsputtering discharges," Vacuum, vol. 47, pp. 307-311, 1996.

[65] N. Hosokawa, T. Tsukada, and T. Misumi, "Self-sputtering phenomena in high-rate coaxial cylindrical magnetron sputtering," J. Vac. Sci. Technol., vol. 14, pp. 143-146, 1977.

[66] W. M. Posadowski and Z. Radzimski, "Sustained self-sputtering using a direct current magnetron source," J. Vac. Sci. Technol. A, vol. 11, pp. 2980-2984, 1993.

[67] E. Klawuhn, G. C. D'Couto, K. A. Ashtiani, P. Rymer, M. A. Biberger, and K. B. Levy, "Ionized physical-vapor deposition using a hollow-cathode magnetron source for advanced metallization," J. Vac. Sci. Technol. A, vol. 18, pp. 1546-1549, 2000.

[68] L. Y. Abramovich, B. N. Klyarfel'd, and Y. N. Nastich, "Super-dense glow discharge with hollow cathode," Zh. Tekh. Fiz., vol. 36, pp. 714-719, 1966.

[69] O. A. Malkin and A. V. Pyshnov, "Investigation of the flow of a large current pulse through a gas," Zhurnal Prikladnoi Spektroskopii, vol. 14, pp. 198-202, 1971.

[70] O. A. Malkin, Impulsnij Tok i Relaksatsija w Gaze (Impulse Current and Relaxation in Gases). Moscow: Atomizdat, 1974.

[71] E. M. Oks and A. A. Chagin, "High-current magnetron discharge in a plasma electron emitter," Sov. Phys. Tech. Phys., vol. 33, pp. 702-704, 1988.

[72] E. M. Oks and A. A. Chagin, "Generation of a hollow electron beam of microsecond duration in a source with a plasma cathode," Sov. Phys. Tech. Phys., vol. 34, pp. 1210-1211, 1989.

[73] M. A. Gundersen and G. Schaefer, Eds., Physics and Applications of Pseudosparks. Springer, 1990.

[74] A. Anders, S. Anders, M. A. Gundersen, and A. M. Martsinovskii, "Self-sustained self-sputtering: A possible mechanism for the superdense glow phase of a pseudospark," IEEE Trans. Plasma Sci., vol. 23, pp. 275-282, 1995.

[75] I. K. Fetisov, A. A. Filippov, G. V. Khodachenko, D. V. Mozgrin, and A. A. Pisarev, "Impulse irradiation plasma technology for film deposition," Vacuum, vol. 53, pp. 133-136, 1999. 
[76] R. Gruen, "Process and apparatus for coating conducting pieces using a pulsed glow discharge," US Patent 5,015,493, 1991.

[77] A. P. Ehiasarian, P. E. Hovsepian, L. Hultman, and U. Helmersson, "Comparison of microstructure and mechanical properties of chromium nitride-based coatings deposited by high power impulse magnetron sputtering and by the combined steered cathodic arc/unbalanced magnetron technique," Thin Solid Films, vol. 457, pp. 270-277, 2004.

[78] K. Tsuruta, K. Skiya, and G. Watanabe, "Velocities of copper and silver ions generated from an impulse vacuum arc," IEEE Trans. Plasma Sci., vol. 25, pp. 603-608, 1997.

[79] D. V. Mozgrin, I. K. Fetisov, and G. V. Khodachenko, "High-current low-pressure quasi-stationary discharge in a magnetic field: Eperimental research," Plasma Phys. Rep., vol. 21, pp. 400-409, 1995.

[80] S. P. Bugaev, N. N. Koval, N. S. Sochugov, and A. N. Zakharov, "Investigation of a high-current pulsed magnetron discharge initiated in the low-pressure diffuse arc plasma," in XVIIth Int. Symp. Discharges and Electrical Insulation in Vacuum, Berkeley, CA, 1996, pp. 1074-1076.

[81] V. Kouznetsov, K. Macak, J. M. Schneider, U. Helmersson, and I. Petrov, "A novel pulsed magnetron sputter technique utilizing very high target power densities," Surf. Coat. Technol., vol. 122, pp. 290-293, 1999.

[82] J. Vlcek, A. D. Pajdarova, and J. Musil, "Pulsed dc magnetron discharge and their utilization in plasma surface engineering," Contrib. Plasma Phys., vol. 44, pp. 426 - 436, 2004.

[83] U. Helmersson, M. Lattemann, J. Bohlmark, A. P. Ehiasarian, and J. T. Gudmundsson, "Ionized physical vapor deposition (IPVD): A review of technology and applications," Thin Solid Films, vol. 513, pp. 1-24, 2006.

[84] T. Kubart, M. Čada, D. Lundin, and Z. Hubička, "Investigation of ionized metal flux fraction in HiPIMS discharges with Ti and Ni targets," Surf. Coat. Technol., vol. 238, pp. 152-157, 2014.

[85] M. Hála, O. Zabeida, B. Baloukas, J. E. Klemberg-Sapieha, and L. Martinu, "Time- and speciesresolved plasma imaging as a new diagnostic approach for HiPIMS discharge characterization," IEEE Trans. Plasma Sci., vol. 38, pp. 3035-3039, 2010.

[86] D. Horwat and A. Anders, "Spatial distribution of average charge state and deposition rate in high power impulse magnetron sputtering of copper," J. Phys. D: Appl. Phys., vol. 41, pp. 135210-1-, 2008.

[87] J. Andersson, A. P. Ehiasarian, and A. Anders, "Observation of $\mathrm{Ti}^{4+}$ ions in a high power impulse magnetron sputtering plasma," Appl. Phys. Lett., vol. 93, p. 071504, 2008. 
[88] R. L. Boxman, D. M. Sanders, and P. J. Martin, Eds., Handbook of Vacuum Arc Science and Technology. Park Ridge, N.J.: Noyes Publications, 1995.

[89] B. Jüttner, "Cathode spots of electrical arcs (Topical Review)," J. Phys. D: Appl. Phys., vol. 34, pp. R103-R123, 2001.

[90] A. Anders, "The evolution of ion charge states in cathodic vacuum arc plasmas: a review," Plasma Sources Sci. Technol., vol. 21, p. 035014, 2012.

[91] J. M. Lafferty, Vacuum Arcs - Theory and Applications. New York: Wiley, 1980.

[92] G. A. Mesyats and D. I. Proskurovsky, Pulsed Electrical Discharge in Vacuum. Berlin: SpringerVerlag, 1989.

[93] Z. Insepov and J. Norem, "Can surface cracks and unipolar arcs explain breakdown and gradient limits?," J. Vac. Sci. Technol. A, vol. 31, pp. 011302-10, 2013.

[94] J. Achtert, B. Altrichter, B. Jüttner, P. Pech, H. Pursch, H.-D. Reiner, W. Rohrbeck, P. Siemroth, and H. Wolff, "Influence of surface contaminations on cathode processes of vacuum discharges," Beitr. Plasmaphys., vol. 17, pp. 419-431, 1977.

[95] K. Jakubka and B. Jüttner, "On the influence of surface conditions on the initiation and spot types of unipolar arcs in a Tokamak," J. Nucl. Mat., vol. 102, pp. 259-266, 1981.

[96] S. Coulombe and J. L. Meunier, "Thermo-field emission - a comparative study," J Phys. D: Appl. Phys., vol. 30, pp. 776-780, Mar 71997.

[97] E. Hantzsche, "The thermo-field emission of electrons in arc discharges," Beitr. Plasmaphys., vol. 22, pp. 325-346, 1982.

[98] W. P. Dyke, J. K. Trolan, E. E. Martin, and P.Barbour, "The field emission initiated vacuum arc. I. Experiments on arc initiation," Phys. Rev., vol. 91, pp. 1043-1054, 1953.

[99] R. H. Good Jr. and E. W. Müller, "Field emission," in Handbuch der Physik vol. 21, ed Berlin: Springer, 1956, pp. 176-231.

[100] S. Dushman, "Thermionic emission," Rev. Mod. Phys., vol. 2, pp. 381-476, 1930.

[101] G. A. Mesyats, Explosive Electron Emission. Ekaterinburg: URO Press, 1998.

[102] D. I. Proskurovskii, Electron Emission (in Russ.). Tomsk, Russia: Tomsk State University Press, 2010.

[103] E. Hantzsche, "Arc spot ignition caused by sheath instability," IEEE Trans. Plasma Sci., vol. 25, pp. 527--532, 1997.

[104] G. A. Mesyats, M. B. Bochkarev, A. A. Petrov, and S. A. Barengolts, "On the mechanism of operation of a cathode spot cell in a vacuum arc," Appl. Phys. Lett., vol. 104, p. 184101, 2014. 
[105] A. Anders, B. Yotsombat, and R. Binder, "Correlation between cathode properties, burning voltage, and plasma parameters of vacuum arcs," J. Appl. Phys., vol. 89, pp. 7764-7771, 2001.

[106] J. Kutzner and H. C. Miller, "Ion flux from the cathode region of a vacuum arc," IEEE Trans. Plasma Sci., vol. 17, pp. 688-694, 1989.

[107] N. Vogel and H. Höft, "Cathode spot energy transfer simulated by a focused laser beam," IEEE Trans. Plasma Sci., vol. 17, pp. 638-640, 1989.

[108] S. Anders, A. Anders, K. M. Yu, X. Y. Yao, and I. G. Brown, "On the macroparticle flux from vacuum arc cathode spots," IEEE Trans. Plasma Sci., vol. 21, pp. 440-446, 1993.

[109] R. L. Boxman and S. Goldsmith, "Macroparticle contamination in cathodic arc coatings: Generation, transport and control," Surf. Coat. Technol., vol. 52, pp. 39-50, 1992.

[110] A. Anders, "The fractal nature of cathode spots," IEEE Trans. Plasma Sci., vol. 33, pp. 1456-1464, 2005.

[111] K. K. Zabello, Y. A. Barinov, A. M. Chaly, A. A. Logatchev, and S. M. Shkol'nik, "Experimental study of cathode spot motion and burning voltage of low-current vacuum arc in magnetic field," IEEE Trans. Plasma Sci., vol. 33, pp. 1553-1559, 2005.

[112] J. Rosén and A. Anders, "Material and time dependence of the voltage noise generated by cathodic vacuum arcs," J. Phys. D: Appl. Phys., vol. 38, pp. 4184-4190, 2005.

[113] A. Anders, E. M. Oks, and G. Yu.Yushkov, "Cathodic arcs: Fractal voltage and cohesive energy rule," Appl. Phys. Lett., vol. 86, pp. 211503-1-3, 2005.

[114] M. Schroeder, Fractals, Chaos, Power Laws: Minutes from an Infinite Paradise, 8th ed. New York: W.H.Freeman and Company, 2000.

[115] T. Schülke and P. Siemroth, "Vacuum arcs cathode spots as a self-similarity phenomenon," IEEE Trans. Plasma Sci., vol. 24, pp. 63-64, 1996.

[116] G. A. Mesyats, "Ecton mechanism of the vacuum arc cathode spot," IEEE Trans. Plasma Sci., vol. 23, pp. 879-883, 1995.

[117] G. A. Mesyats, "Ecton Mechanism of the Cathode Spot Phenomena in a Vacuum Arc," IEEE Trans. Plasma Sci., vol. 41, pp. 676-694, 2013.

[118] O. Monteiro and A. Anders, "Vacuum-arc-generated macroparticles in the nanometer range," IEEE Trans. Plasma Sci., vol. 27, pp. 1030-1033, 1999.

[119] S. A. Barengolts, G. A. Mesyats, and M. M. Tsventoukh, "The ecton mechanism of unipolar arcing in magnetic confinement fusion devices," Nuclear Fusion, vol. 50, p. 125004, 2010. 
[120] S. Barengolts, G. Mesyats, and M. Tsventoukh, "Initiation of ecton processes by interaction of a plasma with a microprotrusion on a metal surface," J. Exp. Theor. Phys., vol. 107, pp. 1039-1048, 2008.

[121] C. Z. Antoine, F.Peauger, and F.LePimpec, "Electromigration occurences and its effects on metallic surfaces submitted to high electromagnetic field: A novel approach to breakdown in accelerators," Nucl. Instrum. Meth. Phys. Res. A, vol. 665, pp. 54-69, 2011.

[122] V. A. Ivanov, B. Jüttner, and H. Pursch, "Time-resolved measurements of the parameters of arc cathode plasmas in vacuum," IEEE Trans. Plasma Sci., vol. 13, pp. 334-336, 1985.

[123] S. Anders and A. Anders, "Frozen state of ionization in a cathodic plasma jet of a vacuum arc," $J$. Phys. D: Appl. Phys., vol. 21, pp. 213-215, 1988.

[124] M. N. Saha, "Ionization in the solar chromosphere," Philosophical Magazine Series 6, vol. 40, pp. 472-488, 1920.

[125] A. Anders, "Ion charge state distributions of vacuum arc plasmas: The origin of species," Phys. Rev. E, vol. 55, pp. 969-981, 1997.

[126] A. Anders and G. Y. Yushkov, "Puzzling differences in bismuth and lead plasmas: evidence for the significant role of neutrals in cathodic vacuum arcs," Appl. Phys. Lett., vol. 91, p. 091502, 2007.

[127] A. Anders, E. M. Oks, and G. Y. Yushkov, "Production of neutrals and their effects on the ion charge states in cathodic vacuum arc plasmas," J. Appl. Phys., vol. 102, p. 043303, 2007.

[128] B. M. Smirnov, "Tables for cross sections of the resonant charge exchange process," Physica Scripta, vol. 61, pp. 595-602, 2000.

[129] A. Anders and G. Y. Yushkov, "Ion flux from vacuum arc cathode spots in the absence and presence of magnetic fields," J. Appl. Phys., vol. 91, pp. 4824-4832, 2002.

[130] E. Byon and A. Anders, "Ion energy distribution functions of vacuum arc plasmas," J. Appl. Phys., vol. 93, pp. 1899-1906, 2003.

[131] J. Kutzner and H. C. Miller, "Integrated ion flux emitted from the cathode spot region of a diffuse vacuum arc," J. Phys. D: Appl. Phys., vol. 25, pp. 686-693, 1992.

[132] C. Wieckert, "The expansion of the cathode spot plasma in vacuum arc discharges," Phys. Fluids, vol. 30, pp. 1810-1813, 1987.

[133] A. Anders, "Cohesive energy rule for vacuum arcs," in Emerging Applications of Vacuum-ArcProduced Plasma, Ion and Electron Beams, I. Brown and E. Oks, Eds., ed Dordrecht: Kluwer Academic Publishers, 2002, pp. 1-14. 
[134] P. Siemroth and H.-J. Scheibe, "The method of laser-sustained arc ignition," IEEE Trans. Plasma Sci., vol. 18, pp. 911-916, 1990.

[135] R. A. MacGill, M. R. Dickinson, A. Anders, O. R. Monteiro, and I. G. Brown, "Streaming metal plasma generation by vacuum arc plasma guns," Rev. Sci. Instrum., vol. 69, pp. 801-803, 1998.

[136] A. Anders, I. G. Brown, R. A. MacGill, and M. R. Dickinson, "'Triggerless" triggering of vacuum arcs," J. Phys. D: Appl. Phys., vol. 31, pp. 584-587, 1998.

[137] I. Zhirkov, A. O. Eriksson, A. Petruhins, M. Dahlqvist, A. S. Ingason, and J. Rosen, "Effect of Ti-Al cathode composition on plasma generation and plasma transport in direct current vacuum arc," J. Appl. Phys., vol. 115, pp. -, 2014.

[138] Z. Werner, J. Stanisawski, J. Piekoszewski, E. A. Levashov, and W. Szymczyk, "New types of multicomponent hard coatings deposited by arc PVD on steel pre-treated by pulsed plasma beam," Vacuum, vol. 70, pp. 263-267, 2003.

[139] S. R. Rossnagel and J. Hopwood, "Metal ion deposition from ionized magnetron sputtering discharge," J. Vac. Sci. Technol. B, vol. 12, pp. 449-453, 1994.

[140] K. Macák, V. Kouznetsov, J. Schneider, U. Helmersson, and I. Petrov, "Ionized sputter deposition using an extremely high plasma density pulsed magnetron discharge," J. Vac. Sci. Technol. A, vol. 18, pp. 1533-1537, 2000.

[141] J. W. Bradley, S. Thompson, and Y. A. Gonzalvo, "Measurement of the plasma potential in a magnetron discharge and the prediction of the electron drift speeds," Plasma Sources Sci. Technol., vol. 10, pp. 490-501, 2001.

[142] J. Sanders, A. Rauch, R. Mendelsberg, and A. Anders, "A synchronized emissive probe for timeresolved plasma potential measurements of pulsed discharges," Rev. Sci. Instrum., vol. 82, p. 093505, 2011.

[143] A. Rauch, R. Mendelsberg, J. M. Sanders, and A. Anders, "Plasma potential mapping of high power impulse magnetron sputtering discharges," J. Appl. Phys., vol. 111, p. 083302, 2012.

[144] B. Chapman, Glow Discharge Processes: Sputtering and Plasma Etching. New York: Wiley, 1980.

[145] D. Depla and S. Mahieu, Eds., Reactive Sputter Deposition. Heidelberg: Springer, 2008.

[146] A. Anders, P. Ni, and A. Rauch, "Drifting localization of ionization runaway: Unraveling the nature of anomalous transport in high power impulse magnetron sputtering," J. Appl. Phys., vol. 111, p. 053304, 2012. 
[147] A. Kozyrev, N. Sochugov, K. Oskomov, A. Zakharov, and A. Odivanova, "Optical studies of plasma inhomogeneities in a high-current pulsed magnetron discharge," Plasma Physics Reports, vol. 37, pp. 621-627, 2011.

[148] A. P. Ehiasarian, A. Hecimovic, T. de los Arcos, R. New, V. Schulz-von der Gathen, M. Böke, and J. Winter, "High power impulse magnetron sputtering discharges: instabilities and plasma selforganization," Appl. Phys. Lett., vol. 100, p. 114101, 2012.

[149] N. Brenning, D. Lundin, T. Minea, C. Costin, and C. Vitelaru, "Spokes and charged particle transport in HiPIMS magnetrons," J. Phys. D: Appl. Phys., vol. 46, p. 084005, 2013.

[150] S. Gallian, W. N. G. Hitchon, D. Eremin, T. Mussenbrock, and R. P. Brinkmann, "A phenomenological model for the description of rotating spokes in HiPIMS discharges," Plasma Sources Sci. Technol., vol. 22, p. 055012, 2013.

[151] D. L. Tang, S. F. Geng, X. M. Qiu, and P. K. Chu, "Three-dimensional numerical investigation of electron transport with rotating spoke in a cylindrical anode layer Hall plasma accelerator " Phys. Plasmas, vol. 20, p. 014702, 2012.

[152] C. L. Ellison, Y. Raitses, and N. J. Fisch, "Cross-field electron transport induced by a rotating spoke in a cylindrical Hall thruster," Phys. Plasmas, vol. 19, p. 013503, 2012.

[153] P. J. Lomas and J. D. Kilkenny, "Electrothermal instabilities in a Hall accelerator," Plasma Physics, vol. 19, p. 329, 1977.

[154] A. Anders, J. Andersson, and A. Ehiasarian, "High power impulse magnetron sputtering: Currentvoltage-time characteristics indicate the onset of sustained self-sputtering," J. Appl. Phys., vol. 102, pp. 113303-1-11, 2007.

[155] N. Hosokawa, T. Tsukada, and H. Kitahara, "Effect of discharge current and sustained selfsputtering," Proc. 8th Int. Vacuum Congress, Le Vide, Cannes, France, 1980, pp. 11-14.

[156] W. M. Posadowski, "Sustained self sputtering of different materials using dc magnetron," Vacuum, vol. 46, pp. 1017-1020, 1995.

[157] J. Andersson and A. Anders, "Gasless sputtering: Opportunities for ultraclean metallization, coatings in space, and propulsion," Appl. Phys. Lett., vol. 92, p. 221503, 2008.

[158] J. Andersson and A. Anders, "Self-sputtering far above the runaway threshold: an extraordinary metal ion generator," Phys. Rev. Lett., vol. 102, p. 045003, 2009.

[159] A. Anders, J. Čapek, M. Hála, and L. Martinu, "The 'recycling trap': A generalized explanation of discharge runaway in high power impulse magnetron sputtering," J. Phys. D: Appl. Phys., vol. 45, p. 012003, 2012. 
[160] E. W. McDaniel, Collision Phenomena in lonized Gases. New York: Wiley, 1964.

[161] J. E. Johnson, Introduction to Atomic and Molecular Collisions. New York: Plenum Press, 1982.

[162] F. F. Chen, Plasma Physics and Controlled Fusion. New York: Plenum Press, 1984.

[163] F. M. Penning, "Die Glimmentladung bei niedrigem Druck zwischen koaxialen Zylindern in einem axialen Magnetfeld," Physica, vol. 3, pp. 873-894, 1936.

[164] A. Anders, "Selfsputtering runaway in high power impulse magnetron sputtering: The role of secondary electrons and multiply charged metal ions," Appl. Phys. Lett., vol. 92, p. 201501, 2008.

[165] R. A. Baragiola, E. V. Alonso, J. Ferron, and A. Oliva-Florio, "Ion-induced electron emission from clean metals," Surf. Sci., vol. 90, pp. 240-255, 1979.

[166] C. Huo, D. Lundin, M. A. Raadu, A. Anders, J. T. Gudmundsson, and N. Brenning, "On sheath energization and Ohmic heating in sputtering magnetrons," Plasma Sources Sci. Technol., vol. 22, p. 045005, 2013.

[167] A. D. Pajdarová, J. Vlček, P. Kudláček, and J. Lukáš, "Electron energy distributions and plasma parameters in high-power pulsed magnetron sputtering discharges," Plasma Sources Sci. Technol., vol. 18, p. 025008, 2009.

[168] A. Anders, "Self-organization and self-limitation in high power impulse magnetron sputtering," Appl. Phys. Lett., vol. 100, p. 224104, 2012.

[169] A. Anders, M. Panjan, R. Franz, J. Andersson, and P. Ni, "Drifting potential humps in ionization zones: the "propeller blades" of high power impulse magnetron sputtering," Appl. Phys. Lett., vol. 103, p. 144103, 2013.

[170] J. Andersson, P. Ni, and A. Anders, "Spectroscopic imaging of self-organization in high power impulse magnetron sputtering plasmas," Appl. Phys. Lett., vol. 103, p. 054104, 2013.

[171] C. Charles, "A review of recent laboratory double layer experiments," Plasma Sources Sci. Technol., vol. 16, p. R1, 2007.

[172] M. Aiempanakit, U. Helmersson, A. Aijaz, P. Larsson, R. Magnusson, J. Jensen, and T. Kubart, "Effect of peak power in reactive high power impulse magnetron sputtering of titanium dioxide," Surf. Coat. Technol., vol. 205, pp. 4828-4831, 2011.

[173] M. Palmucci, N. Britun, T. Silva, R. Snyders, and S. Konstantinidis, "Mass spectrometry diagnostics of short-pulsed HiPIMS discharges," J. Phys. D: Appl. Phys., vol. 46, p. 215201, 2013.

[174] M. Panjan, R. Franz, and A. Anders, "Azimuthally asymmetric particle fluxes in sputtering magnetrons, and their amplification by ionization zones in high power impulse magnetron sputtering," Plasma Sources Sci. Technol., vol. 23, p. 025007, 2014. 
[175] P. A. Ni, C. Hornschuch, M. Panjan, and A. Anders, "Plasma flares in high power impulse magnetron sputtering," Appl. Phys. Lett., vol. 101, pp. 224102-5, 2012.

[176] D. Horwat and A. Anders, "Compression and strong rarefaction in high power impulse magnetron sputtering discharges," J. Appl. Phys., vol. 108, p. 123306, 2010.

[177] R. Chistyakov, B. Abraham, W. Sproul, J. Moore, and J. Lin, "Modulated pulse power technology and deposition for protective and tribological coatings," 50th Annual Technical Conference Proceedings of the Society of Vacuum Coaters, Louisville, KY, 2007, pp. 139-143.

[178] L. Meng, A. N. Cloud, S. Jung, and D. N. Ruzic, "Study of plasma dynamics in a modulated pulsed power magnetron discharge using a time-resolved Langmuir probe," J. Vac. Sci. Technol. A, vol. 29, pp. 011024-7, 2011.

[179] J. Lin, B. Wang, Y. Ou, W. D. Sproul, I. Dahan, and J. J. Moore, "Structure and properties of CrSiN nanocomposite coatings deposited by hybrid modulated pulsed power and pulsed dc magnetron sputtering," Surf. Coat. Technol., vol. 216, pp. 251-258, 2013.

[180] J. Lin, B. Wang, W. D. Sproul, Y. Ou, and I. Dahan, "Anatase and rutile $\mathrm{TiO}_{2}$ films deposited by arc-free deep oscillation magnetron sputtering," J. Phys. D: Appl. Phys., vol. 46, p. 084008, 2013.

[181] R. Franz, C. Clavero, R. Bolat, R. Mendelsberg, and A. Anders, "Observation of multiple charge states and high ion energies in high-power impulse magnetron sputtering (HiPIMS) and burst HiPIMS using a LaB 6 target," Plasma Sources Sci. Technol., vol. 23, p. 035001, 2014.

[182] A. N. Odivanova, V. G. Podkovyrov, N. S. Sochugov, and K. V. Oskomov, "Study of the plasma parameters in a high-current pulsed magnetron sputtering system," Plasma Phys. Rep., vol. 37, pp. 239-243, 2011.

[183] J. Hopwood, "Ionized physical vapor deposition of integrated circuit interconnects," Phys. Plasmas, vol. 5, pp. 1624-1631, 1998.

[184] V. Stranak, Z. Hubicka, M. Cada, S. Drache, M. Tichy, and R. Hippler, "Investigation of ionized metal flux in enhanced high power impulse magnetron sputtering discharges," J. Appl. Phys., vol. 115, p. 153301, 2014.

[185] G. Y. Yushkov and A. Anders, "Origin of the delayed current onset in high power impulse magnetron sputtering," IEEE Trans. Plasma Sci., vol. 38, pp. 3028-3034, 2010.

[186] E. Oks and A. Anders, "Evolution of the plasma composition of a high power impulse magnetron sputtering system studied with a time-of-flight spectrometer," J. Appl. Phys., vol. 105, pp. 093304-1-9, 2009. 
[187] E. M. Oks and A. Anders, "Boron-rich plasma by high power impulse magnetron sputtering of lanthanum hexaboride," J. Appl. Phys., vol. 112, p. 086103, 2012.

[188] A. E. Ross, R. Sanginés, B. Treverrow, M. M. M. Bilek, and D. R. McKenzie, "Optimizing efficiency of Ti ionized deposition in HIPIMS," Plasma Sources Sci. Technol., vol. 20, p. 035021, 2011.

[189] A. P. Ehiasarian, A. Vetushka, A. Hecimovic, and S. Konstantinidis, "Ion composition produced by high power impulse magnetron sputtering discharges near the substrate," J. Appl. Phys., vol. 104, 2008.

[190] R. J. Adler and S. T. Picraux, "Repetitively pulsed metal ion beams for ion implantation," Nucl. Instrum. Meth. Phys. Res. B, vol. 6, pp. 123-128, 1985.

[191] J. R. Conrad, J. L. Radtke, R. A. Dodd, F. J. Worzala, and N. C. Tran, "Plasma source ionimplantation technique for surface modification," J. Appl. Phys., vol. 62, pp. 4591-4596, 1987.

[192] A. Anders, S. Anders, I. G. Brown, M. R. Dickinson, and R. A. MacGill, "Metal plasma immersion ion implantation and deposition using vacuum arc plasma sources," J. Vac. Sci. Technol. B, vol. 12, pp. 815-820, 1994.

[193] Y. Lifshitz, S. R. Kasai, J. W. Rabalais, and W. Eckstein, "Subplantation model for film growth from hyperthermal species," Phys. Rev. B, vol. 41, pp. 10468-10480, 1990.

[194] A. Anders, "Metal plasma immersion ion implantation and deposition: a review," Surf. Coat. Technol., vol. 93, pp. 158-167, 1997.

[195] W.-D. Münz, D. Schulze, and F. J. M. Hauzer, "A new method for hard coatings - ABS (arc bond sputtering)," Surf. Coat. Technol., vol. 50, pp. 169-178, 1992.

[196] W. D. Münz, F. J. M. Hauzer, D. Schulze, and B. Buil, "A new concept for physical vapor deposition coating combining the methods of arc evaporation and unbalanced-magnetron sputtering " Surf. Coat. Technol., vol. 49, pp. 161-167, 1991.

[197] A. P. Ehiasarian, A. Anders, and I. Petrov, "Combined filtered cathodic arc etching pretreatmentmagnetron sputter deposition of highly adherent CrN films," J. Vac. Sci. Technol. A, vol. 25, pp. 543-550, 2007.

[198] Y. P. Purandare, A. P. Ehiasarian, and P. E. Hovsepian, "Deposition of nanoscale multilayer $\mathrm{CrN} / \mathrm{NbN}$ physical vapor deposition coatings by high power impulse magnetron sputtering," J. Vacuum Sci. Technol. A, vol. 26, pp. 288-296, 2008.

[199] R. Machunze, A. P. Ehiasarian, F. D. Tichelaar, and G. C. A. M. Janssen, "Stress and texture in HIPIMS TiN thin films," Thin Solid Films, vol. 518, pp. 1561-1565, 2009. 
[200] M. Lattemann, A. P. Ehiasarian, J. Bohlmark, P. A. O. Persson, and U. Helmersson, "Investigation of high power impulse magnetron sputtering pretreated interfaces for adhesion enhancement of hard coatings on steel," Surf. Coat. Technol., vol. 200, pp. 6495-6499, 2006.

[201] I. G. Brown, A. Anders, S. Anders, R. A. Castro, M. R. Dickinson, R. A. MacGill, and Z. Wang, "Synthesis of unattainable ion implantation profiles - "Pseudo-implantation"," Nucl. Instrum. Meth. Phys. Res. B, vol. 106, pp. 646-650, 1995.

[202] W. Olbrich and G. Kampschulte, "Superimposed pulse bias voltage used in arc and sputter technology," Surf. Coat. Technol., vol. 59, pp. 274-280, 1993.

[203] R. Bandorf, S. Falkenau, K. Schiffmann, H. Gerdes, and U. Heckmann, "Properties of Nichrome sputtered by HIPIMS in unipolar and DC-superimposed Mode," 51st Ann. Techn. Conf. Proc. of the Society of Vacuum Coaters, Chicago, IL, 2008, pp. 317-320.

[204] M. Vergöhl, O. Werner, S. Bruns, T. Wallendorf, and G. Mark, "Superimposed MF-HiPIMS Processes for the Deposition of $\mathrm{ZrO}_{2}$ Thin Films," 51st Annual Technical Conference of the Society of Vacuum Coaters, Chicago, IL, 2008, pp. 307-312.

[205] Y. Lifshitz, S. R. Kasi, and J. W. Rabalais, "Subplantation model for film growth from hyperthermal species: application to diamond," Phys. Rev. Lett., vol. 62, pp. 1290-1293, 1989.

[206] S.-Y. Chun and A. Chayahara, "Nucleation and growth of vacuum arc deposited gold films under pulsed bias," Surf. Coat. Technol., vol. 137, pp. 241-245, 2001.

[207] W. Olbrich, J. Fessmann, G. Kampschulte, and J. Ebberink, "Improved control of TiN coating properties using cathodic arc evaporation with a pulsed bias," Surf. Coat. Technol., vol. 49, pp. 258-262, 1991.

[208] W. Olbrich and G. Kampschulte, "Additional ion bombardment in PVD processes generated by a superimposed pulse bias voltage," Surf. Coat. Technol., vol. 61, pp. 262-267, 1993.

[209] A. Anders, N. Pasaja, and S. Sansongsiri, "Filtered cathodic arc deposition with ion-speciesselective bias," Rev. Sci. Instrum., vol. 78, p. 063901, 2007.

[210] R. Ben-Ami, V. N. Zhitomirsky, R. L. Boxman, and S. Goldsmith, "Plasma distribution in a triplecathode vacuum arc deposition apparatus," Plasma Sources Sci. Technol., vol. 8, pp. 355-362, 1999.

[211] D. R. McKenzie, "Tetrahedral bonding in amorphous carbon," Rep. Prog. Phys., vol. 59, pp. 16111664, 1996.

[212] J. Robertson, "Diamond-like amorphous carbon," Mat. Sci. Eng., vol. R 37, pp. 129-281, 2002. 
[213] S. Sansongsiri, B. Yodsombat, and A. Anders, "Electrical properties of a-C:Mo films produced by dual-cathode filtered cathodic arc plasma deposition," Diamond Rel. Mat., vol. 17, pp. 208020832008.

[214] J. L. Endrino, A. Anders, J. M. Albella, J. A. Horton, T. H. Horton, P. R. Ayyalasomayajula, and M. Allen, "Antibacterial efficacy of advanced silver-amorphous carbon coatings deposited using the pulsed dual cathodic arc technique," J. Phys. Conf. Ser., vol. 252, p. 012012, 2010.

[215] G. Greczynski and L. Hultman, "Time and energy resolved ion mass spectroscopy studies of the ion flux during high power pulsed magnetron sputtering of $\mathrm{Cr}$ in $\mathrm{Ar}$ and $\mathrm{Ar} / \mathrm{N} 2$ atmospheres," Vacuum, vol. 84, pp. 1159-1170, 2010.

[216] W. Breilmann, "Dynamic of film growth during high power pulsed magnetron sputtering (HiPIMS) of titanium," J. Phys. D: Appl. Phys., vol. 46, p. 485204, 2013.

[217] F. Mitschker, M. Prenzel, J. Benedikt, C. Maszl, and A. von Keudell, "Time-resolved measurement of film growth during HIPIMS of titanium," J. Phys. D: Appl. Phys., vol. 46, p. 155204, 2013.

[218] G. Greczynski, J. Lu, J. Jensen, I. Petrov, J. E. Greene, S. Bolz, W. Kolker, C. Schiffers, O. Lemmer, and L. Hultman, "Metal versus rare-gas ion irradiation during $\mathrm{Ti}_{1-x} \mathrm{Al}_{x} \mathrm{~N}$ film growth by hybrid high power pulsed magnetron/dc magnetron co-sputtering using synchronized pulsed substrate bias," J. Vac. Sci. Technol. A, vol. 30, p. 061504, 2012.

[219] A. Anders, N. Pasaja, S. H. N. Lim, T. C. Petersen, and V. J. Keast, "Plasma biasing to control the growth conditions of diamond-like carbon," Surf. Coat. Technol., vol. 201, pp. 4628-4632, 2007.

[220] A. Anders, "Approaches to rid cathodic arc plasma of macro- and nanoparticles: a review," Surf. Coat. Technol., vol. 120-121, pp. 319-330, 1999.

[221] I. I. Aksenov, V. A. Belous, and V. G. Padalka, "A device for producing coatings in vacuum (in Russian)," USSR 605425, 1976.

[222] I. I. Aksenov, V. A. Belous, V. G. Padalka, and V. M. Khoroshikh, "Apparatus to rid the plasma of a vacuum arc of macroparticles," Instrum. Exp. Tech., vol. 21, pp. 1416-1418, 1978.

[223] I. L. Aksenov, V. G. Padalka, V. T. Tolok, and V. M. Khoroshikh, "Flow of a vacuum arc plasma in a linear plasma-optical system," Fizika Plazmy, vol. 6, pp. 918-924, 1980.

[224] I. I. Aksenov, A. N. Belokhvostikov, V. G. Padalka, N. S. Repalov, and V. M. Khoroshikh, "Plasma flux motion in a toroidal plasma guide," Plasma Phys. Controlled Fusion, vol. 28, pp. 761-770, 1986. 
[225] I. I. Aksenov, V. A. Belous, V. V. Vasil'ev, Y. Y. Volkov, and V. E. Strel'nitskij, "A rectilinear plasma filtering system for vacuum-arc deposition of diamond-like carbon coatings," Diamond Rel. Mater., vol. 8, pp. 468-471, 1999.

[226] I. I. Aksenov, A. A. Andreev, V. A. Belous, V. E. Strel'nitskii, and V. M. Khoroshikh, Vacuum Arc: Plasma Sources, Deposition of Coatings, Surface Modification (in Russian). Kiev, Ukraine: Naukova Dumka, 2012.

[227] A. Anders, S. Anders, and I. G. Brown, "Transport of vacuum arc plasmas through magnetic macroparticle filters," Plasma Sources Sci. Technol., vol. 4, pp. 1-12, 1995.

[228] M. M. M. Bilek and A. Anders, "Designing advanced filters for macroparticle removal from cathodic arc plasmas," Plasma Sources Sci. Technol., vol. 8, pp. 488-493, 1999.

[229] A. Anders, "Physics of arcing, and implications to sputter deposition," Thin Solid Films, vol. 502, pp. 22-28, 2006.

[230] J. Vetter, "Coating device for coating a substrate and coating method," WO Patent 2006/000862 Al, 2006.

[231] J. Bohlmark, M. Ostbye, M. Lattemann, H. Ljungcrantz, T. Rosell, and U. Helmersson, "Guiding the deposition flux in an ionized magnetron discharge," Thin Solid Films, vol. 515, pp. 1928-1931, 2006.

[232] A. Anders and J. Brown, "A plasma lens for magnetron sputtering," IEEE Trans. Plasma Sci., vol. 39, pp. 2528-2529, 2011.

[233] A. Goncharov, "Invited review article: The electrostatic plasma lens," Rev. Sci. Instrum., vol. 84, p. 021101, 2013.

[234] A. I. Morozov and S. V. Lebedev, "Plasma Optics," in Reviews of Plasma Physics, Vol. 8, M. A. Leontovich, Ed., ed New York: Consultants Bureau, 1980, pp. 301-460.

[235] S. Mráz and J. M. Schneider, "Influence of the negative oxygen ions on the structure evolution of transition metal oxide thin films," J. Appl. Phys., vol. 100, p. 023503, 2006.

[236] S. Mráz and J. M. Schneider, "Energy distribution of $\mathrm{O}^{-}$ions during reactive magnetron sputtering," Appl. Phys. Lett., vol. 89, p. 051502, 2006.

[237] T. Minami, T. Miyata, T. Yamamoto, and H. Toda, "Origin of electrical property distribution on the surface of ZnO:Al films prepared by magnetron sputtering," J. Vac. Sci. Technol. A, vol. 18, pp. 1584-1589, 2000.

[238] K. Ellmer and T. Welzel, "Reactive magnetron sputtering of transparent conductive oxide thin films: Role of energetic particle (ion) bombardment," J. Mater. Res., vol. 27, pp. 765-779, 2012. 
[239] T. Welzel and K. Ellmer, "Negative oxygen ion formation in reactive magnetron sputtering processes for transparent conductive oxides," J. Vac. Sci. Technol. A, vol. 30, pp. 061306-12, 2012.

[240] N. Tsukamoto, D. Watanabe, M. Saito, Y. Sato, N. Oka, and Y. Shigesato, "In situ analyses on negative ions in the sputtering process to deposit Al-doped ZnO films," J. Vac. Sci. Technol. A, vol. 28 , pp. 846-850, 2010.

[241] V. Stranak, A.-P. Herrendorf, H. Wulff, S. Drache, M. Cada, Z. Hubicka, M. Tichy, and R. Hippler, "Deposition of rutile (TiO2) with preferred orientation by assisted high power impulse magnetron sputtering," Surf. Coat. Technol., 2013.

[242] M. Bowes, P. Poolcharuansin, and J. W. Bradley, "Negative ion energy distributions in reactive HiPIMS," J. Phys. D: Appl. Phys., vol. 46, p. 045204, 2013.

[243] A. Amin, D. Köhl, and M. Wuttig, "The role of energetic ion bombardment during growth of $\mathrm{TiO}_{2}$ thin films by reactive sputtering," J. Phys. D: Appl. Phys., vol. 43, p. 405303, 2010.

[244] M. Bowes and J. W. Bradley, "Inert gas effects on the deposition rate of $\mathrm{TiO}_{2}$ during reactive HiPIMS," Surf. Coat. Technol., vol. 250, pp. 2-6, 2014.

[245] B. K. Tay, Z. W. Zhao, and D. H. C. Chua, "Review of metal oxide films deposited by filtered cathodic vacuum arc technique," Mat. Sci. Eng. R: Reports, vol. 52, pp. 1-48, 2006.

[246] A. Anders, S. H. N. Lim, K. M. Yu, J. Andersson, J. Rosén, M. McFarland, and J. Brown, "High quality ZnO:Al transparent conducting oxide films synthesized by pulsed filtered cathodic arc deposition," Thin Solid Films, vol. 518, pp. 3313-3319, 2010.

[247] R. J. Mendelsberg, S. H. N. Lim, Y. K. Zhu, J. Wallig, D. J. Milliron, and A. Anders, "Achieving high mobility ZnO:Al at very high growth rates by dc filtered cathodic arc deposition," J. Phys. D: Appl. Phys., vol. 44, p. 232003, 2011.

[248] Y. Zhu, R. J. Mendelsberg, J. Zhu, J. Han, and A. Anders, "Transparent and conductive indium doped cadmium oxide thin films prepared by pulsed filtered cathodic arc deposition," Appl. Surf. Sci., vol. 265, pp. 738-744, 2013.

[249] Y. Zhu, R. J. Mendelsberg, J. Zhu, J. Han, and A. Anders, "Structural, optical, and electrical properties of indium-doped cadmium oxide films prepared by pulsed filtered cathodic arc deposition," J. Mater. Sci., vol. 48, pp. 3789-3797, 2013.

[250] S. Goldsmith, "Filtered vacuum arc deposition of undoped and doped ZnO thin films: Electrical, optical, and structural properties," Surf. Coat. Technol., vol. 201, pp. 3993-3999, 2006. 
[251] V. N. Zhitomirsky, E. Çetinörgü, E. Adler, Y. Rosenberg, R. L. Boxman, and S. Goldsmith, "Filtered vacuum arc deposition of transparent conducting Al-doped ZnO films," Thin Solid Films, vol. 515, pp. 885-890, 2006.

[252] D. Horwat and A. Anders, "Ion acceleration and cooling in gasless self-sputtering," Appl. Phys. Lett., vol. 97, p. 221501, 2010.

[253] A. Hecimovic and A. P. Ehiasarian, "Spatial and temporal evolution of ion energies in high power impulse magnetron sputtering plasma discharge," J. Appl. Phys., vol. 108, p. 063301, 2010.

[254] J. M. Schneider, A. Anders, and G. Y. Yushkov, "Magnetic-field-dependent plasma composition of a pulsed aluminum arc in an oxygen ambient," Appl. Phys. Lett., vol. 78, pp. 150-152, 2001.

[255] E. M. Oks, A. Anders, I. G. Brown, M. R. Dickinson, and R. A. MacGill, "lon charge state distributions in high current vacuum arc plasma in a magnetic field," IEEE Trans. Plasma Sci., vol. 24, pp. 1174-1183, 1996.

[256] A. Anders, "Time-dependence of ion charge state distributions of vacuum arcs: An interpretation involving atoms and charge exchange collisions," IEEE Trans. Plasma Sci., vol. 33, pp. 205-209, 2005.

[257] A. P. Ehiasarian, R. New, W.-D. Münz, L. Hultman, U. Helmersson, and V. Kouznetsov, "Influence of high power densities on the composition of pulsed magnetron plasmas," Vacuum, vol. 65, pp. 147-154, 2002.

[258] M. Hala, N. Viau, O. Zabeida, J. E. Klemberg-Sapieha, and L. Martinu, "Dynamics of reactive highpower impulse magnetron sputtering discharge studied by time- and space-resolved optical emission spectroscopy and fast imaging," J. Appl. Phys., vol. 107, p. 043305, 2010.

[259] A. Hecimovic and A. P. Ehiasarian, "Time evolution of ion energies in HIPIMS of chromium plasma discharge," J. Phys. D: Appl. Phys., vol. 42, p. 135209, 2009.

[260] M. Hála, O. Zabeida, J. E. Klemberg-Sapieha, and L. Martinu, "Dynamics of HiPIMS discharge operated in oxygen," IEEE Trans. Plasma Sci., vol. 39, pp. 2582-2583, 2011.

[261] Y. Purandare, A. Ehiasarian, A. Santana, and P. Hovsepian, "ZrN coatings deposited by high power impulse magnetron sputtering and cathodic arc techniques," J. Vac. Sci. Technol. A, vol. 32, p. 031507, 2014.

[262] I. G. Brown, B. Feinberg, and J. E. Galvin, "Multiply stripped ion generation in the metal vapor vacuum arc," J. Appl. Phys., vol. 63, pp. 4889-4898, 1988.

[263] V. F. Puchkarev and A. M. Murzakayev, "Current density and the cathode spot lifetime in a vacuum arc at threshold currents," J. Phys. D: Appl. Phys., vol. 23, pp. 26-35, 1990. 
[264] N. Vogel and B. Jüttner, "Measurements of the current density in arc cathode spots from the Zeeman splitting of emission lines," J. Phys. D: Appl. Phys., vol. 24, pp. 922-927, 1991.

[265] P. Siemroth, T. Schülke, and T. Witke, "Microscopic high speed investigations of vacuum arc cathode spot," IEEE Trans. Plasma Sci., vol. 23, pp. 919-925, 1995.

[266] A. Batrakov, N. Vogel, S. E. Popov, D. Proskurovsky, D. Kudimov, and D. Nikitine, "Interferograms of a cathode spot plasma obtained with a picosecond laser," IEEE Trans. Plasma Sci., vol. 30, pp. 106-107, 2002.

[267] A. Anders, S. Anders, B. Jüttner, and H. Lück, "High-resolution imaging of vacuum arc cathode spots," IEEE Trans. Plasma Sci., vol. 24, pp. 69-70, 1996.

[268] F. Magnus, T. K. Tryggvason, S. Olafsson, and J. T. Gudmundsson, "Current--voltage--time characteristics of the reactive $\mathrm{Ar} / \mathrm{O}_{2}$ high power impulse magnetron sputtering discharge," $J$. Vac. Sci. Technol. A, vol. 30, p. 050601, 2012.

[269] A. Anders, S. Anders, B. Jüttner, W. Bötticher, H. Lück, and G. Schröder, "Pulsed dye laser diagnostics of vacuum arc cathode spots," IEEE Trans. Plasma Sci., vol. 20, pp. 466-472, 1992.

[270] B. Jüttner, H. Pursch, and S. Anders, "On the current density at the cathode of vacuum arcs," J. Phys. D: Appl. Phys., vol. 17, pp. L111-L114, 1984.

[271] J. Bohlmark, J. Alami, C. Christou, A. Ehiasarian, and U. Helmersson, "Ionization of sputtered metals in high power pulsed magnetron sputtering," J. Vac. Sci. Technol. A, vol. 23, pp. 18-22, 2005.

[272] A. Vetushka and A. P. Ehiasarian, "Plasma dynamic in chromium and titanium HIPIMS discharges," J. Phys. D: Appl. Phys., vol. 41, p. 015204, 2008.

[273] I. G. Brown, "Vacuum arc ion sources," Rev. Sci. Instrum., vol. 65, pp. 3061-3081, 1994.

[274] R. Franz, P. Polcik, and A. Anders, "Ion charge state distributions of Al and Cr in cathodic arc plasmas from composite cathodes in vacuum, argon, nitrogen, and oxygen," IEEE Trans. Plasma Sci., vol. 41, pp. 1929 - 1937, 2013.

[275] T. Schülke and A. Anders, "Ion charge state distributions of alloy-cathode vacuum arc plasmas," IEEE Trans. Plasma Sci., vol. 27, pp. 911-914, 1999.

[276] M. W. Thompson, "The energy spectrum of ejected atoms during the high energy sputtering of gold," Phil. Mag., vol. 18, pp. 377 - 414, 1968.

[277] M. Aiempanakit, A. Aijaz, D. Lundin, U. Helmersson, and T. Kubart, "Understanding the discharge current behavior in reactive high power impulse magnetron sputtering of oxides," J. Appl. Phys., vol. 113, p. 133302, 2013. 
[278] A. Anders, "Unfiltered and filtered cathodic arc deposition," in Handbook of Deposition Technologies for Films and Coatings (Third Edition) P. M. Martin, Ed., ed Norwich, NY: William Andrew Publishing, 2010, pp. 466-531.

[279] F. Sanchette, C. Ducros, T. Schmitt, P. Steyer, and A. Billard, "Nanostructured hard coatings deposited by cathodic arc deposition: From concepts to applications," Surface and Coatings Technology, vol. 205, pp. 5444-5453, 2011.

[280] P. J. Martin and A. Bendavid, "Review of the filtered vacuum arc process and materials deposition," Thin Solid Films, vol. 394, pp. 1-15, 2001.

[281] V. Gorokhovsky, C. Bowman, D. VanVorous, and J. Wallace, "Deposition of various metal, ceramic, and cermet coatings by an industrial-scale large area filtered arc deposition process," J. Vac. Sci. Technol. A, vol. 27, pp. 1080-1095, 2009.

[282] D. Carter, H. Walde, and K. Nauman, "Managing arcs in large area sputtering applications," Thin Solid Films, vol. 520, pp. 4199-4202, 2012.

[283] D. J. Christie, F. Tomasel, W. D. Sproul, and D. C. Carter, "Power supply with arc handling for high peak power magnetron sputtering," J. Vac. Sci. Technol. A, vol. 22, pp. 1415-1419, 2004.

[284] C. Mitterer, O. Heuze, and V.-H. Derflinger, "Substrate and coating damage by arcing during sputtering," Surf. Coat. Technol., vol. 89, pp. 233-238, 1997.

[285] H. Takikawa, R. Miyano, T. Sakakibara, A. Bendavid, P. J. Martin, A. Matsumuro, and K. Tsutsumi, "Effect of substrate bias on AIN thin film preparation in shielded reactive vacuum arc deposition," Thin Solid Films, vol. 386, pp. 276-280, 2001.

[286] P. C. Johnson and H. Randhawa, "Zirconium nitride films prepared by cathodic arc plasma deposition process," Surf. Coat. Technol., vol. 33, pp. 53-62, 1987.

[287] J. Vetter, W. Burgmer, H. G. Dederichs, and A. J. Perry, "The architecture and performance of multilayer and compositionally gradient coatings made by cathodic arc evaporation," Surf. Coat. Technol., vol. 61, pp. 209-214, 1993.

[288] H. Takikawa, T. Matsui, T. Sakakibara, A. Bendavid, and P. J. Martin, "Properties of titanium oxide film prepared by reactive cathodic vacuum arc deposition," Thin Solid Films, vol. 348, pp. 145-151, 1999.

[289] Y.-M. Chen, B. Liao, X.-Y. Wu, H.-X. Zhang, and X. Zhang, "Synthesis and characterization of zirconium oxynitride coatings deposited by filtered cathodic vacuum arc technology," Surf. Coat. Technol., vol. 228, p. S210, 2013. 
[290] A. O. Eriksson, N. Ghafoor, J. Jensen, L. Å. Näslund, M. P. Johansson, J. Sjölen, M. Odén, L. Hultman, and J. Rosen, "Arc deposition of Ti-Si-C-N thin films from binary and ternary cathodes - Comparing sources of C," Surf. Coat. Technol., vol. 213, pp. 145-154, 2012.

[291] J. Alami, K. Sarakinos, F. Uslu, and M. Wuttig, "On the relationship between the peak target current and the morphology of chromium nitride thin films deposited by reactive high power pulsed magnetron sputtering," J. Phys. D: Appl. Phys., vol. 42, p. 015304, 2009.

[292] A. Guillaumot, F. Lapostolle, C. Dublanche-Tixier, J. C. Oliveira, A. Billard, and C. Langlade, "Reactive deposition of Al-N coatings in Ar/N2 atmospheres using pulsed-DC or high power impulse magnetron sputtering discharges," Vacuum, vol. 85, pp. 120-125, 2010.

[293] S. Shayestehaminzadeh, T. K. Tryggvason, L. Karlsson, S. Olafsson, and J. T. Gudmundsson, "The properties of TiN ultra-thin films grown on $\mathrm{SiO} 2$ substrate by reactive high power impulse magnetron sputtering under various growth angles," Thin Solid Films, vol. 548, pp. 354-357, 2013.

[294] M. Balzer and M. Fenker, "Three-dimensional thickness and property distribution of TiC films deposited by DC magnetron sputtering and HIPIMS," Surf. Coat. Technol., vol. 250, pp. 37-43, 2014.

[295] M. Aiempanakit, T. Kubart, P. Larsson, K. Sarakinos, J. Jensen, and U. Helmersson, "Hysteresis and process stability in reactive high power impulse magnetron sputtering of metal oxides," Thin Solid Films, vol. 519, pp. 7779-7784, 2011.

[296] M. Hála, J. Čapek, O. Zabeida, J. E. Klemberg-Sapieha, and L. Martinu, "Hysteresis-free deposition of niobium oxide films by HiPIMS using different pulse management strategies," $J$. Phys. D: Appl. Phys., vol. 45, p. 055204, 2012.

[297] A. Hemberg, J.-P. Dauchot, R. Snyders, and S. Konstantinidis, "Evaporation-assisted high-power impulse magnetron sputtering: The deposition of tungsten oxide as a case study," J. Vac. Sci. Technol. A, vol. 30, p. 040604, 2012.

[298] S. Konstantinidis, A. Hemberg, J. P. Dauchot, and M. Hecq, "Deposition of zinc oxide layers by high-power impulse magnetron sputtering," J. Vac. Sci. Technol. B, vol. 25, pp. L19-L21, 2007.

[299] V. Sittinger, O. Lenck, M. Vergöhl, B. Szyszka, and G. Bräuer, "Applications of HIPIMS metal oxides," Thin Solid Films, vol. 548, pp. 18-26, 2013.

[300] S. Sønderby, A. Aijaz, U. Helmersson, K. Sarakinos, and P. Eklund, "Deposition of yttria-stabilized zirconia thin films by high power impulse magnetron sputtering and pulsed magnetron sputtering," Surf. Coat. Technol., vol. 240, p. 1, 2014. 
[301] A. Surpi, T. Kubart, D. Giordani, M. Tosello, G. Mattei, M. Colasuonno, and A. Patelli, "HiPIMS deposition of TiOx in an industrial-scale apparatus: Effects of target size and deposition geometry on hysteresis," Surf. Coat. Technol., vol. 235, pp. 714-719, 2013.

[302] F. Horstmann, V. Sittinger, and B. Szyszka, "Heat treatable indium tin oxide films deposited with high power pulse magnetron sputtering," Thin Solid Films, vol. 517, pp. 3178-3182, 2009.

[303] G. Kamath, A. P. Ehiasarian, Y. Purandare, and P. E. Hovsepian, "Tribological and oxidation behaviour of TiAICN/VCN nanoscale multilayer coating deposited by the combined HIPIMS/(HIPIMS-UBM) technique," Surf. Coat. Technol., vol. 205, pp. 2823-2829, 2011.

[304] J. C. Walker, I. M. Ross, C. Reinhard, W. M. Rainforth, and P. E. Hovsepian, "High temperature tribological performance of CrAIYN/CrN nanoscale multilayer coatings deposited on $\mathrm{\gamma}$-TiAl," Wear, vol. 267, pp. 965-975, 2009.

[305] H. Randhawa, "High-rate deposition of $\mathrm{Al}_{2} \mathrm{O}_{3}$ films using modified cathodic arc plasma deposition processes," J. Vac. Sci. Technol. A, vol. 7, pp. 2346-2349, 1989.

[306] Y. S. Choong, B. G. Tay, S. P. Lau, X. Shi, and Y. H. Cheng, "High deposition rate of aluminum oxide film by off-plane double bend filtered cathodic arc techniques," Thin Solid Films, vol. 386, pp. 1-5, 2001.

[307] T. W. H. Oates, J. Pigott, D. R. McKenzie, and M. M. M. Bilek, "A high-current pulsed cathodic vacuum arc plasma source," Rev. Sci. Instrum., vol. 74, pp. 4750-4754, 2003.

[308] P. Siemroth, J. Berthold, B. Petereit, H. H. Schneider, and H. Hilgers, "A new generation of filtered arc sources for ultrathin top coats on magnetic hard disks," Surf. Coat. Technol., vol. 188189, pp. 684-690, 2004.

[309] M. Samuelsson, D. Lundin, J. Jensen, M. A. Raadu, J. T. Gudmundsson, and U. Helmersson, "On the film density using high power impulse magnetron sputtering," Surf. Coat. Technol., vol. 205, pp. 591-596, 2010.

[310] A. Anders, "Deposition rates of high power impulse magnetron sputtering: physics and economics," J. Vac. Sci. Technol. A, vol. 28, pp. 783-790, 2010.

[311] J. Emmerlich, S. Mraz, R. Snyders, K. Jiang, and J. M. Schneider, "The physical reason for the apparently low deposition rate during high-power pulsed magnetron sputtering," Vacuum, vol. 82, pp. 867-870, 2008.

[312] J. Lin, W. D. Sproul, J. J. Moore, S. Lee, and S. Myers, "High rate deposition of thick $\mathrm{CrN}$ and $\mathrm{Cr}_{2} \mathrm{~N}$ coatings using modulated pulse power (MPP) magnetron sputtering," Surf. Coat. Technol., vol. 205, pp. 3226-3234, 2011. 
[313] K. Sarakinos, J. Alami, C. Klever, and M. Wuttig, "Process stabilization and enhancement of deposition rate during reactive high power pulsed magnetron sputtering of zirconium oxide," Surf. Coat. Technol., vol. 202, pp. 5033-5035, 2008.

[314] F. R. Weber, F. Fontaine, M. Scheib, and W. Bock, "Cathodic arc evaporation of (Ti,Al)N coatings and (Ti,Al)N/TiN multilayer-coatings--correlation between lifetime of coated cutting tools, structural and mechanical film properties," Surf. Coat. Technol., vol. 177-178, pp. 227-232, 2004.

[315] D. A. Karpov, "Cathodic arc sources and macroparticle filtering," Surf. Coat. Technol., vol. 96, pp. 22-33, 1997.

[316] J. L. Endrino, D. Horwat, A. Anders, J. Andersson, and R. Gago, "Impact of annealing on the conductivity of amorphous carbon films incorporating copper and gold nanoparticles deposited by pulsed dual cathodic arc," Plasma Process. Polym., vol. 6, pp. S438-S443, 2009.

[317] L. Ryves, M. M. M. Bilek, T. W. H. Oates, R. N. Tarrant, D. R. McKenzie, F. A. Burgmann, and D. G. McCulloch, "Synthesis and in-situ ellipsometric monitoring of $\mathrm{Ti} / \mathrm{C}$ nanostructured multilayers using a high-current, dual source pulsed cathodic arc," Thin Solid Films, vol. 482, pp. 133-137, 2005.

[318] J. Rosén, L. Ryves, P. O. Å. Persson, and M. M. M. Bilek, "Deposition of epitaxial Ti ${ }_{2} A I C$ thin films by pulsed cathodic arc," J. Appl. Phys., vol. 101, p. 056101, 2007.

[319] A. Mockute, P. O. Å. Persson, F. Magnus, A. S. Ingason, S. Olafsson, L. Hultman, and J. Rosen, "Synthesis and characterization of arc deposited magnetic $(\mathrm{Cr}, \mathrm{Mn})_{2} \mathrm{AIC}$ MAX phase films," physica status solidi (RRL) - Rapid Research Letters, vol. 8, pp. 420-423, 2014.

[320] V. Kirchhoff, T. Kopte, T. Winkler, M. Schulze, and P. Wiedemuth, "Dual magnetron sputtering (DMS) system with sine-wave power supply for large-area coating," Surf. Coat. Technol., vol. 98, pp. 828-833, 1998.

[321] J. O'Brien and P. J. Kelly, "Characterisation studies of the pulsed dual cathode magnetron sputtering process for oxide films," Surf. Coat. Technol., vol. 142-144, pp. 621-627, 2001.

[322] J. Musil and P. Baroch, "Discharge in dual magnetron sputtering system," IEEE Trans. Plasma Sci., vol. 33, pp. 338-339, 2005.

[323] V. Stranak, M. Cada, Z. Hubicka, M. Tichy, and R. Hippler, "Time-resolved investigation of dual high power impulse magnetron sputtering with closed magnetic field during deposition of Ti--Cu thin films," J. Appl. Phys., vol. 108, pp. 043305-8, 2010. 
[324] V. Stranak, S. Drache, M. Cada, Z. Hubicka, M. Tichy, and R. Hippler, "Time-resolved diagnostics of dual high power impulse magnetron sputtering with pulse delays of $15 \mu \mathrm{s}$ and $500 \mu \mathrm{s}, "$ Contrib. Plasma Phys., vol. 51, pp. 237-245, 2011.

[325] A. Anders, R. J. Mendelsberg, S. Lim, M. Mentink, J. L. Slack, J. G. Wallig, A. V. Nollau, and G. Y. Yushkov, "Deposition of niobium and other superconducting materials with high power impulse magnetron sputtering: Concept and first results (Invited)," 15th International Conference on RF Superconductivity, Chicago, II, 2011, p. http://accelconf.web.cern.ch/AccelConf/SRF2011/papers/tuioa06.pdf.

[326] V. Stranak, S. Drache, R. Bogdanowicz, H. Wulff, A.-P. Herrendorf, Z. Hubicka, M. Cada, M. Tichy, and R. Hippler, "Effect of mid-frequency discharge assistance on dual-high power impulse magnetron sputtering," Surf. Coat. Technol., vol. 206, pp. 2801-2809, 2012.

[327] L. Hultman, C. Engstrom, and M. Oden, "Mechanical and thermal stability of TiN/NbN superlattice thin films," Surf. Coat. Technol., vol. 133-134, pp. 227-233, 2000.

[328] N. Bagcivan, K. Bobzin, and S. Theiß, "Synthesis of nano-structured HPPMS CrN/AIN coatings," J. Phys. D: Appl. Phys., vol. 46, p. 084001, 2013.

[329] P. Eklund, M. Beckers, U. Jansson, H. Högberg, and L. Hultman, "The Mn + 1AXn phases: Materials science and thin-film processing," Thin Solid Films, vol. 518, pp. 1851-1878, 2010.

[330] A. P. Ehiasarian, "High-power impulse magnetron sputtering and its applications," Pure Appl. Chem., vol. 82, pp. 1247-1258, 2010.

[331] E. Broitman, Z. Czigány, G. Greczynski, J. Böhlmark, R. Cremer, and L. Hultman, "Industrial-scale deposition of highly adherent CNx films on steel substrates," Surf. Coat. Technol., vol. 204, pp. 3349-3357, 2010.

[332] M. Samuelsson, K. Sarakinos, H. Högberg, E. Lewin, U. Jansson, B. Wälivaara, H. Ljungcrantz, and U. Helmersson, "Growth of Ti-C nanocomposite films by reactive high power impulse magnetron sputtering under industrial conditions," Surf. Coat. Technol., vol. 206, pp. 2396-2402, 2012.

[333] A. Atiser, S. Mraz, and J. M. Schneider, "Pressure dependence of the Al ion energy distribution functions during filtered cathodic arc thin film growth in an $\mathrm{Ar}, \mathrm{O}_{2}$ ambient," J. Phys. D: Appl. Phys., vol. 42, p. 015202, 2009. 